PNNL-11047

UC-810

Project Technical Information

Technical Letter Report:

Submerged Bed Scrubber

Sediment Resuspension

Testing for the Hanford Waste

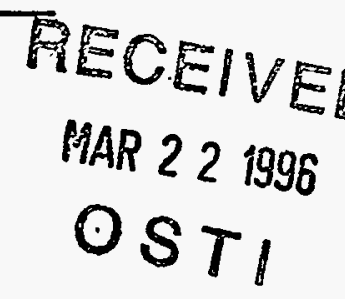

Vitrification Plant
A. J. Schmidt
M. G. Herrington

March 1996

Prepared for the U.S. Department of Energy under Contract DE-AC06-76RLO 1830

Pacific Northwest National Laboratory Operated for the U.S. Department of Energy by Battelle Memorial Institute

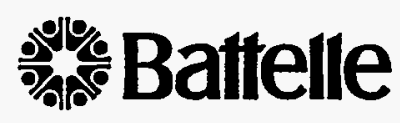

DISTRIBUTION OF THIS DOCUMENT IS UNLIMITED 8 S

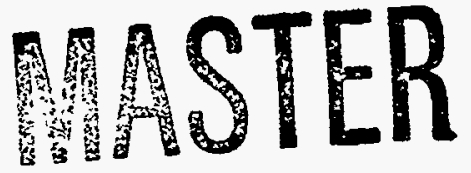




\title{
Technical Letter Report: Submerged Bed Scrubber Sediment Resuspension Testing for the Hanford Waste Vitrification Plant
}

\author{
A. J. Schmidt \\ M: G. Herrington
}

March 1996

Prepared for

the U.S. Department of Energy

under Contract DE-AC06-76RLO 1830

Pacific Northwest National Laboratory

Richland, Washington 99352 


\title{
DISCLAIAYER
}

This report wes piepared as an account of work sponsored by an agency of the United States Government. Neither the Uniied States Covernment nor any agency thereof, nor Earielle Miemorial instituie, nor any of their employees, makes any warranty, express or implied, or assumes any legal lia bility or responsibility for the accuracy, completeness, or.usefulness of any information, apparatus, product, or process disclosed, or represents that its use would not infringe privately owned rights. Reference hejein io eny speciñc commerciel product, process, or senvice by

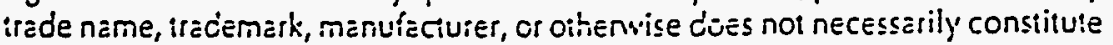
or imply its endorsement, recommenciation, or favoring by the United States Government or any agency thereof, or Banielle Memorial Instiilie. The views and opinions of authors expressed herein do not necessarily state or reilect those of the United States Government or any agency thereof.

\author{
PACIFIC NORTHWEST NATIONAL LABORATORY \\ operaied by \\ BATTELLE \\ for the \\ UNITED STATES DEPARTMENT OF ENERGY \\ under Contract DE-ACO6-j6RLO 1830
}
Printed in the United States of America
Available to DOE and DOE contractors from the

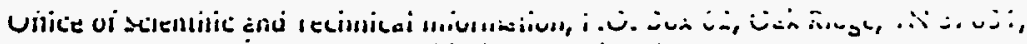 prices available from (615) 576-8401.

Available to the public from the National Technical Information Service, U.S. Depariment of Commerce, 5285 Port Royal Rd., Springield, VA 22161 


\section{CONTENTS}

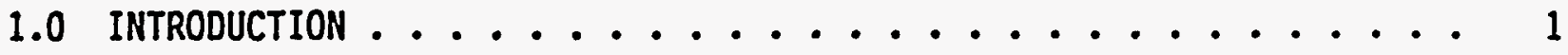

2.0 CONCLUSIONS AND RECOMMENDATIONS .............. 3

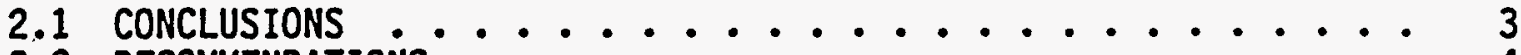

2.2 RECOMMENDATIONS ...................... 4

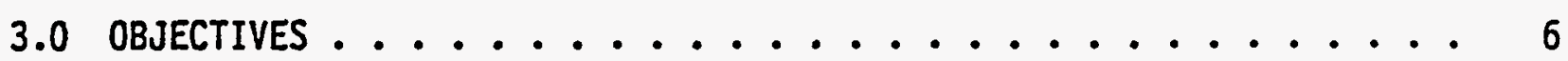

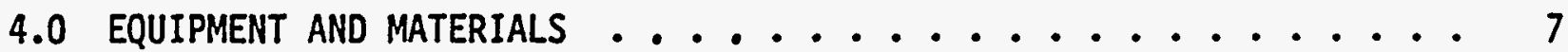

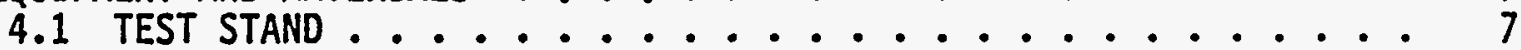

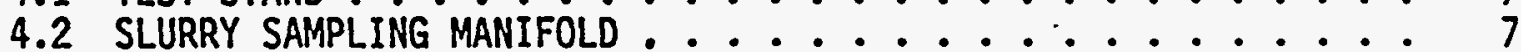

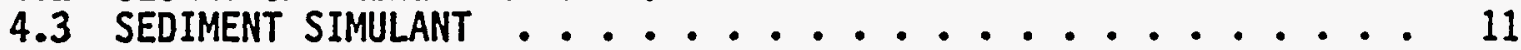

5.0 EXPERIMENTAL APPROACH ....................... 15

5.1 JET PATTERNS HITH TRACER PARTICLES ........... 15

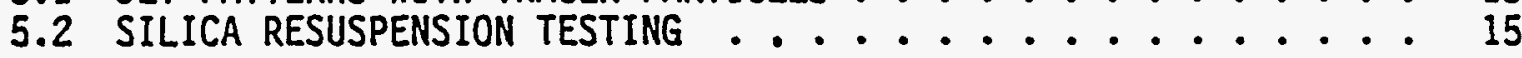

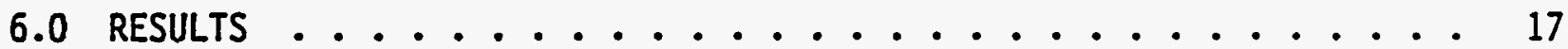

APPENDIX A - OPTICAL ANALYSES PARTICLE SIZE DISTRIBUTION DATA FOR SILICA AND PSCM-23 SBS SEDIMENT

APPENDIX B - PROCEDURES FOR SEDIMENT RESUSPENSION TESTING 


\section{FIGURES}

FIGURE 4.1. Configuration and Dimensions of Physical Model Test Stand

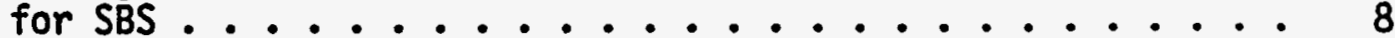

FIGURE 4.2. 6-in. Perforated Pipe Sparger ........... 9 FIGURE 4.3. Plan View of the Test Tank ............ 10 FIGURE 4.4. Viscosity of Large and Small Silica as a Function of Mixing

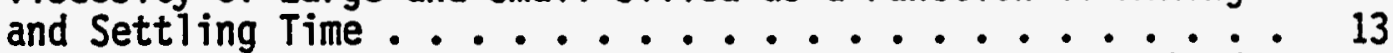

FIGURE 6.1. Area of Tank Bottom Influenced by Sparge Jets as Determined by Observations of Movement of Tracer Particles . . . . . 18

FIGURE 6.2. Area of Tank Bottom Cleaned of Large Silica . . . . . . . 21 FIGURE 6.3. Area of Tank Bottom Cleaned of Small Silica . . . . . . . 22 FIGURE 6.4. Resuspended Silica as a Function of Cleaned Area ..... 23 FIGURE 6.5. Overlay of Cleaning Areas (after 60 Min of Sparge Operation) onto Plan-View of HWVP SBS. ........... 25

\section{$\underline{\text { TABLES }}$}

TABLE 4.1. Size Distribution of SBS Sediment and Silica Simulants . . 11 TABLE 4.2. Viscosity Versus Time for Small and Large Silica ...... 12 TABLE 6.1. Tabular Results of Resuspension Testing ......... 19 


\subsection{INTRODUCTION}

During vitrification operations in the Hanford Waste Vitrification Plant (HWVP), some feed components will be vented from the melter to the melter offgas cleaning equipment. The current HWVP reference process for melter off-gas treatment includes a submerged bed scrubber (SBS) to provide the first stage of off-gas scrubbing and quenching.

The SBS is a cylindrical packed bed, submerged in a scrub solution vessel (scrub tank). The melter off-gas to be cleaned enters the bottom of the packed bed through a central downcomer pipe. Vacuum is maintained on the SBS outlet by the off-gas blower to draw the off-gas through the downcomer and up through the bed. The apparent density of the gas/liquid mixture percolating up through the bed is lower than the density of the scrubbing solution in the surrounding scrub tank. This density difference provides a buoyant force that drives liquid circulation in the SBS. In the packed bed, the circulating scrub liquid absorbs heat and collects aerosols from the hot off gas. Additionally, the circulating scrub liquid cleans the packing material and minimizes sediment buildup within the bed.

The SBS was designed to be a self-cleaning device. It was anticipated that the insoluble particulates captured in the scrub solution would be suspended by the recirculation action. As condensed steam is accumulated, scrub solution would overflow from the scrub tank into a receiver tank, and a steady-state concentration of particulates would be maintained in the scrub tank.

During most melter/off-gas test runs at Pacific Northwest Laboratory (PNL) with the Pilot Scale Ceramic Melter (PSCM) and at the West Valley Demonstration Project (WVDP), no significant quantities of sedimentation were accumulated in the SBS scrub tank. However, during test run SF-12, conducted at West Valley, approximately 6 in. of sedimentation accumulated in the scrub tank. This raised concerns that a similar accumulation could occur with the HWVP SBS, If such an accumulation rate occurred during a sustained melter run, the SBS would soon cease to function. To alleviate the potential for sedimentation buildup, the HWVP SBS design includes a sparge ring at the bottom of the scrub tank. The sparge ring will be operated intermittently to prevent buildup of solids which could interfere with circulation with the SBS 
scrub tank.

This report presents the results of testing conducted to evaluate the effectiveness of the HWVP sparge ring design. Section 2 contains the conclusions and recommendations; Section 3 sumnarizes the objectives; Section 4 describes the equipment and materials used; Section 5 gives the experimental approach; and Section 6 discusses the results. The appendices contain procedures for sediment resuspension testing and particle size distribution data for silica and sediment.

In addition to the HWVP SBS sparge ring study, PNL recently performed an evaluation of the sparge ring configuration used to resuspend sediment in SBS at the West Valley Demonstration Project. Some of the observations and results from that study, referred to here as the "WVDP SBS evaluation," have been integrated into this report. 


\subsection{CONCLUSIOHS AND RECOMENDATIONS}

Based on sediment resuspension testing with a test stand modeling a single $15^{\circ}$ sector (with one set of four perforations) of the proposed HWVP sparge ring, the following conclusions and recommendations have been made.

\subsection{CONCLUSIONS}

- If the behavior of the actual HWVP SBS sediment is similar to the silica simulant used in this evaluation, operation of the proposed sparge ring design at $50 \mathrm{gpm}$ will clean $35 \%$ to $43 \%$ of the area of the scrub tank bottom. At $72 \mathrm{gpm}, 67 \%$ to $78 \%$ of the area of the tank bottom may be cleaned. The values are based on the area cleaned in tests which started with an initially uniform distribution of solids. Sufficiently frequent operation of the current sparge ring at 50 or $72 \mathrm{gpm}$ is expected to maintain a circulation path for liquid-within the SBS. Modifications to the sparge ring could increase the degree of resuspension obtained during operation.

- Observations of the sparge behavior with metallic tracer particles in the tank indicated that the areas influenced by the fluid jets from each placement of perforations will extend beyond the $15^{\circ}$ sector. That is, there will be interaction among adjacent jets. Interaction among. jets will create turbulence and eddy currents that may enhance the ability of the jets to resuspend sediment. Since this study investigated a single placement of perforations, the testing results may be conservative.

- At the three flow rates tested $(1,2.1$, and $3 \mathrm{gpm})$, the vertically downward directed jet produced the greatest cleaning radius with both tracer particles and silica sediment. This jet needed to penetrate through 8 in. of liquid to reach the tank bottom. The jet directed at $55^{\circ}$ from the vertical, which was required to penetrate through 15 in. of liquid to reach the tank bottom, exhibited moderate resuspension capabilities at flow rates of $2.1 \mathrm{gpm}$ (design) and $3 \mathrm{gpm}$ with tracer particles and silica sediment. The jets from the two perforations directed at $70^{\circ}$ from the vertical were required to penetrate through 25 in. of liquid before reaching the tank bottom. These jets were marginally effective for silica resuspension only at the highest flow rate tested $(3 \mathrm{gpm})$. These findings indicate that the effectiveness of the sparge ring could be increased by lowering the ring and adjusting the perforation angles.

- The 3/32-in. perforations may be susceptible to plugging. Fluid used in the sparge ring should be filtered to remove particles capable of plugging the holes in the sparge ring. 
- Larger-diameter silica particles (3.1 $\mu \mathrm{m}$ - number mean) proved to be more difficult to resuspend than the smaller silica $(1.5 \mathrm{\mu m}$ - number mean), which more closely resembles solids collected from the SBS during PSCM-23 (1.6 jm - number mean). Unfortunately, the PSCM-23 SBS sediment sample size was not sufficient for viscosity determinations. Although similar in size, it is unknown how well silica simulated the behavior of actual SBS sediment.

- Based on this evaluation and on the WVDP SBS sedimentation resuspension evaluation, it appears that operating the sparge ring for more than 10 min will not significantly increase the quantity of resuspended silica. During sediment resuspension testing, it was observed that the area of the tank bottom swept clean of sediment increased significantly between 10 and 30 min of sparge operation. However, during this time period, the resuspended silica concentration remained essentially constant: It is possible that resuspended silica was settling in areas not influenced by the sparge during and after the initial $10 \mathrm{~min}$ of sparge operation. Because of the cloudiness of the tank during the testing, re-settling could not be confirmed through visual observation. For the SBS resuspension testing, slurry from the test tank was recirculated through the sparge. In the HWVP SBS, clean water may be used as the sparge motive fluid. As clean water is sparged in and slurry is withdrawn, the suspended solids concentration in the SBS will decrease. Continued operation of the sparge ring will continue to dilute the SBS fluid and remove suspended solids.

\subsection{RECOMMENDATIONS}

The following recommendations are based on the HWVP and WVDP SBS sediment resuspension evaluations.

- If it is desired to utilize the concepts in the existing sparge ring design. (as opposed to employing a eductor in the SBS), the following modifications are suggested: The sparge ring should be lowered so that it is approximately 2 in. above the tank bottom. Instead of having four perforations at each placement, the performance could probably be enhanced by having three perforations. The three perforations should have the same combined flow rate $(2.1 . \mathrm{gpm})$, but sized to take advantage of the maximum available head pressure (i.e., 45 psig), which would maximize the jet velocities and provide more energy for resuspending sediment. The perforations. should be arranged so that one is directed vertically downward, and the other two are directed at $10^{\circ}$ below the horizontal --one oriented toward the tank wall and the other towards the center of the tank. These changes would greatly reduce the distances the jets must travel prior to reaching the tank bottom (i.e., more of the jet momentum could be utilized for resuspending sediment rather than in entraining surrounding fluid). The recommendations in this bullet are based on engineering judgement and not actual test data. There is 
confidence that the revised design will provide cleaning superior to the tested configuration which produced marginal cleaning effectiveness. Additional testing would have to be performed to accurately characterize the performance of the revised configuration.

- Because of the small size (3/32-in.-diameter), the perforations on the HWVP sparge ring are very susceptible to plugging. Adequate provisions, such as in line filters, should be made to minimize the number of large particles in the motive fluid stream which could potentially block perforations.

- During the next melter run, a quantity of SBS- sediment should be collected that would be sufficient for performing viscosity measurements to determine how well silica simulates actual sediment. The extent to which the actual sediment flocculates will significantly influence how sediment consolidates on the tank bottom.

- Consideration should be given to building a larger test stand that would allow testing of three adjacent jets. This would enable observation and quantification of jet interaction and would serve as a better model to more accurately predict actual SBS sparge ring performance. 


\subsection{OBJECTIVES}

This evaluation was performed to develop test information requested by Fluor Danie1, Inc., regarding the design and operation of the SBS so that modified features of the SBS can be included in the detailed design of the HWVP melter off-gas system, and so that a planned dynamic simulation of the off-gas system can be performed by Fluor with increased accuracy. Specifically, Fluor requested that PNL evaluate the ability of the sparge ring to resuspend settled solids in the bottom of the SBS (Fluor Item No. 3.2d-SBS Sparge Ring Testing).

The testing objectives and methods were originally outlined in the "Test Plan for Performance Evaluation of the Liquid-Fed Ceramic Melter (LFCM) Submerged Bed Scrubber (SBS)" (WTC-006-25-3). Those testing methods invoived an existing physical model that consisted of a sparge ring section placed in a glass tank in a configuration analogous to the HWVP sparge ring design. Silica flour was used to simulate SBS sediments for the testing. Visual observation and measurements were made to determine the sparge/jet pattern and the effective sparge/jet cleaning distance.

The HWVP SBS design (MOG Submerged Bed Scrubber, SC-14A-001, Rev. 00, 10-16-89) specifies that a 4-ft-diameter sparge ring will be located beneath the 4.-ft-diameter bed and placed concentrically within the 8-ft-diameter scrub tank. The sparge ring is a 2 -in.-diameter, Schedule 40 pipe with 24 sets of $3 / 32-i n$. holes, with 4 holes per set. The hole sets are uniformly spaced on the ring at $15^{\circ}$ arcs.

The design liquid flow rate to the HWVP sparger is $50 \mathrm{gpm}$ (Fluor Daniel Technology Data Needs Item 3.2d). The pressure drop through the holes on the sparger is expected to be approximately $10 \mathrm{psi}$. A maximum header pressure of 45 psig is available. With the existing physical model, one set of holes (four perforations) was examined. The design fluid flow rate to this set of perforations is approximately $2.1 \mathrm{gpm}--$ based on a design flow rate of $50 \mathrm{gpm}$ for the entire sparge ring. At this flow rate the liquid velocity through the perforations will be approximately $25 \mathrm{ft} / \mathrm{sec}$.

The following text describes the equipment and procedures that were used to evaluate the HWVP SBS sparge ring design with respect to resuspending sedimentation, and presents the results of the testing. 


\subsection{EQUIPMENT AND MATERIALS}

Brief descriptions of equipment and materials are provided in this section. More detailed information on equipment, materials; and procedures is provided in Appendix B.

\subsection{TEST STAND}

The existing test apparatus consists of a 90-gal glass tank supported by a Unistrut framework (see Figure 4.1). A 6-in.-long, 2-in. Schedule 40 pipe section was fabricated to replicate a section of the HWVP sparge ring (see Figure 4.2). The perforated pipe section was connected to a pipe equipped with a pressure gage, flow regulator, and rotameter to measure flow rates. Fluid was supplied to the sparge with a centrifugal pump by recirculating fluid drawn from the far end of the glass tank.

As proposed for the HWVP SBS design, the centerline of the sparge section in the test stand was located 9 in. above the bottom of the tank, and 24 in. (horizontally) from the wall. Figure 4.3 shows a plan view of the test tank with an overlay of a $15^{\circ}$ sector of the HWVP SBS.

One end of the test tank was elevated approximately 3 in. so that the bottom of the test tank was sloped to the same angle as the scrub tank fabricated for the LFCM-SBS $\left(3.8^{\circ}\right)$. For the LFCM scrub tank, which has an inside diameter of $60 \mathrm{in.,}$ the bottom rises $4 \mathrm{in.}$ ( (low end to high end).

\subsection{SLURRY SAMPLING MANIFOLD}

A portable sampling manifold was used to withdraw slurry samples while the jet was in operation. The sampling manifold consists of a 30-in.-long section of 1/8-in. stainless steel tubing clamped to a 30-in.-long, 1/2-in.diameter dowel. Flex hose connected the sampling tube to a peristaltic pump. The pump was used to dispense the slurry into a beaker, and the sample was analyzed for weight percent (wt\%) solids. The manifold was hand held in a vertical position perpendicular to the tank bottom. The dowel touched the bottom of the tank while the tube was clamped at a set distance above the tank bottom. 


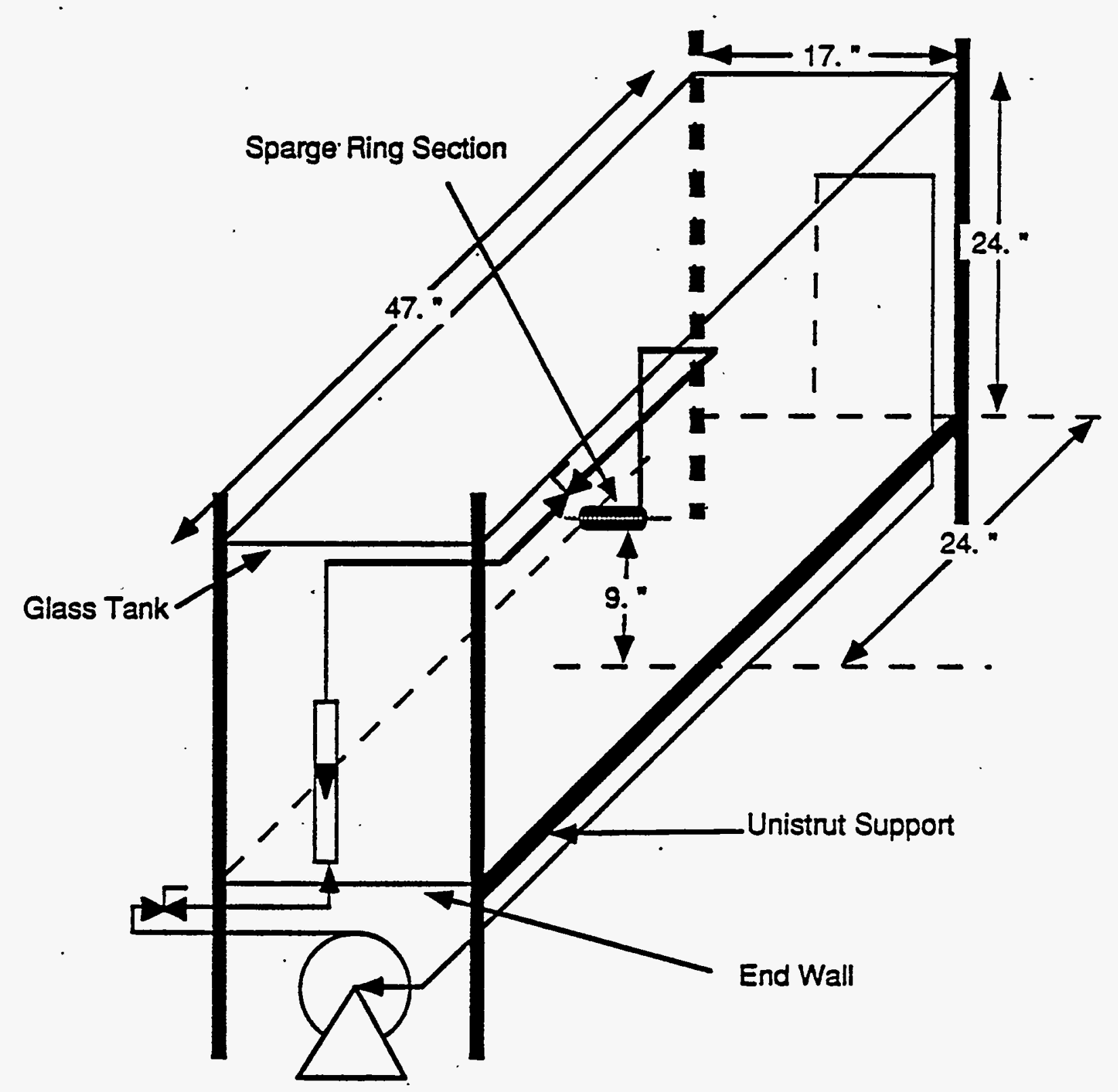

Recycle Water Pump

FIGURE 4.1. Configuration and Dimensions of Physical Model Test Stand for SBS Sparge Ring Evaluation 

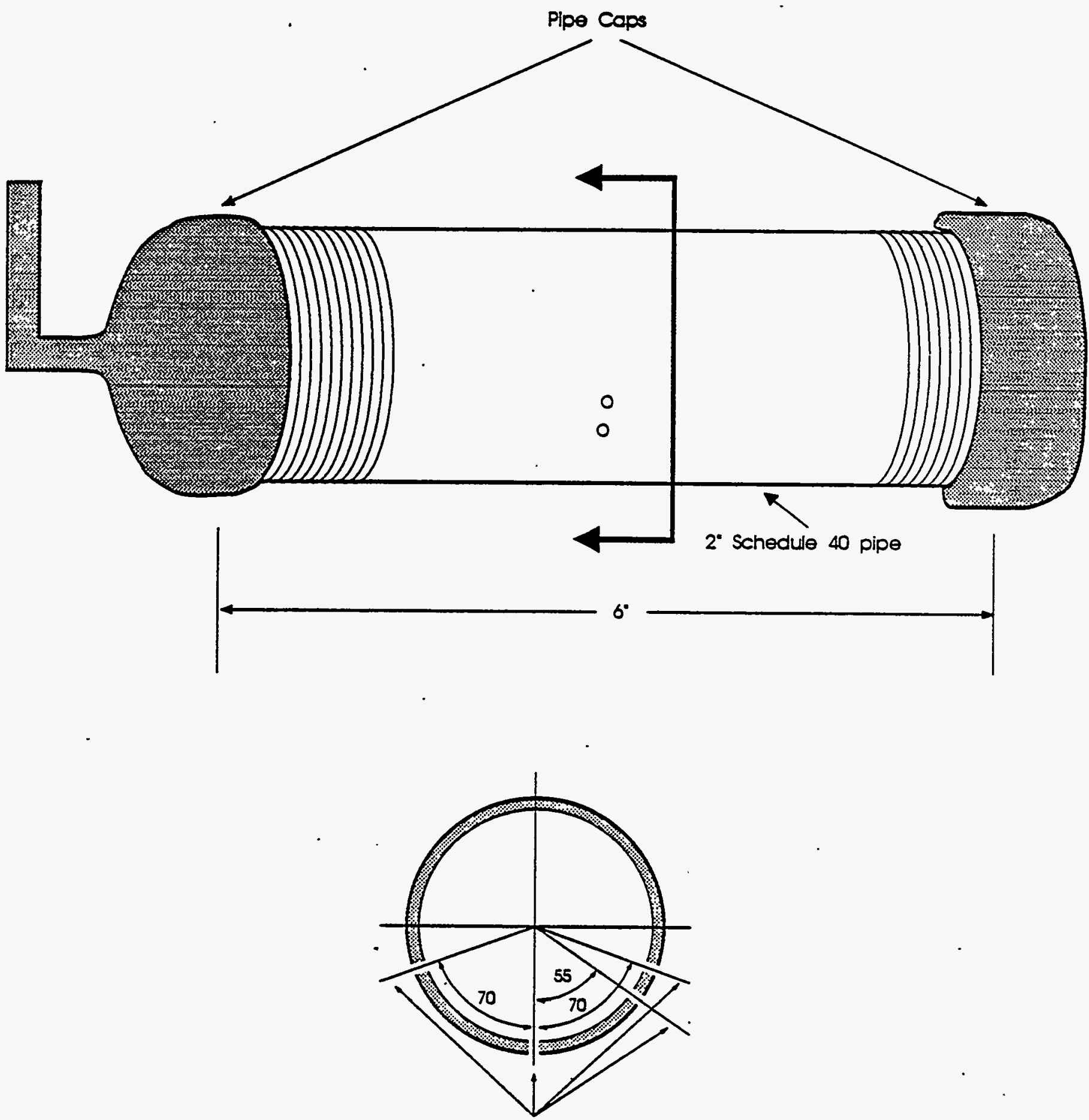

$43 / 32^{\circ}$ holes

FIGURE 4.2. 6-in. Perforated Pipe Sparger 
Tank and Sampling Locatlon Schematlc

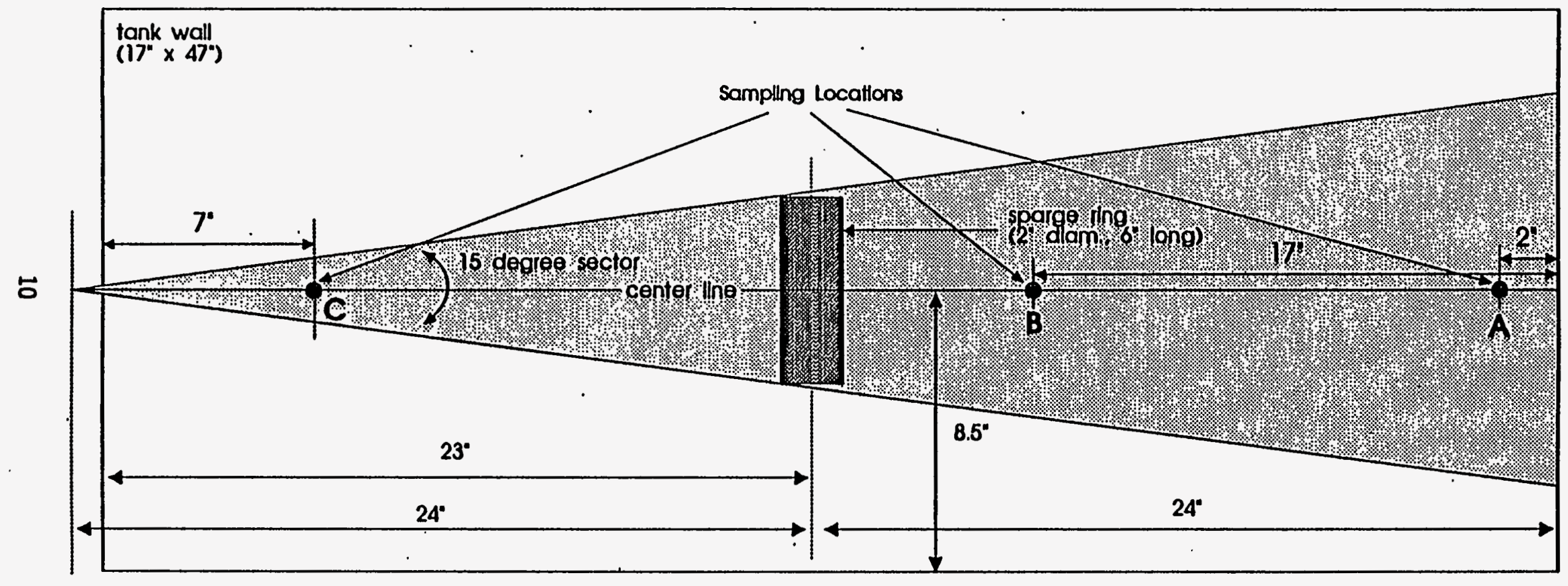

FIGURE 4.3. Plan View of the Test Tank, Sparge Section, and Sampling Locations with an Overlay of a $15^{\circ}$-Sector of the HWVP SBS 


\subsection{SEDIMENT SIMULANT}

Two size classifications of silica flour were used as sediment simulants for the resuspension testing in order to bracket the mean particle size of solids collected in the SBS during PSCM-23. In this report, the larger size is referred to as "large silica" and the smaller size is referred to as "small silica". The large silica [silica type: $7-0,56 \%$ mass $-20 \mu \mathrm{m} ; 44 \%+20 \mu \mathrm{m}$ via Fisher subsizer) was obtained from AGSCO. The small silica used for this evaluation was obtained from 50-1b sacks of "TAMSCO - Ground Silica" stored in the 324 Building chemical warehouse. Particle size distribution data were obtained via optical analysis. The results of the size analysis are shown in Table 4.1. Detailed data from the optical analyses are given in Appendix A.

TABLE 4.1. Size Distribution of SBS Sediment and Silica Simulants

\begin{tabular}{lcc} 
Material & $\begin{array}{c}\text { Mean Equivalent } \\
\text { Diameter }(\mu \mathrm{m})\end{array}$ & $\begin{array}{c}\text { Standard } \\
\text { Deviation }(\mu \mathrm{m})\end{array}$ \\
\cline { 2 - 3 } PSCM-23 Sediment & 1.6 & 1.2 \\
Small Silica & 1.5 & 1.6 \\
Large Silica & 3.1 & 3.0
\end{tabular}

The silica powders used in this work were also used in a WVDP SBS evaluation in which the viscosities of the silica slurries were determined using a Brookfield rotoviscometer. The viscometer has a spindle that was lowered into a settled slurry sample and rotated. Five readings were recorded once a day for 4 consecutive days to determine the viscosity of the settled silica as a function of time. Two slurry samples were tested: one fully mixed prior to testing and the other unmixed (i.e., dry silica was dumped into water with no subsequent mixing). The results of the viscosity testing are tabulated in Table 4.2. The initial viscosity readings were plotted against time (see Figure 4.4) and represent the instantaneous viscosities of the slurry. After several spindle revolutions, the spindle probably bored a small hole in the sediment, which reduced the friction/drag on the spindle, and reduced the viscosity reading. The tabulated results show a substantial decrease in viscosity. after several spindle revolutions. Hence, the initial readings are probably the most accurate. 
TABLE 4.2. Viscosity Versus Time for Small and Large Silica

\begin{tabular}{|c|c|c|c|c|c|}
\hline \multirow[b]{2}{*}{ Day } & \multirow[b]{2}{*}{ Revolution } & \multicolumn{2}{|c|}{ Small Silica } & \multicolumn{2}{|c|}{ Large Silica } \\
\hline & & $\begin{array}{c}\text { Unmixed } \\
\text { (cP) } \\
\end{array}$ & $\begin{array}{l}\text { Mixed } \\
(C P) \\
\end{array}$ & $\begin{array}{l}\text { Unmixed } \\
\text { (CP) } \\
\end{array}$ & $\begin{array}{l}\text { Mixed } \\
(C P) \\
\end{array}$ \\
\hline 0 & $\begin{array}{l}1 \\
2 \\
3 \\
4 \\
5\end{array}$ & $\begin{array}{r}180,000 \\
30,000 \\
30,000 \\
25,000\end{array}$ & $\begin{array}{l}7,200 \\
6,000 \\
6,800 \\
6,800 \\
6,800\end{array}$ & $\begin{array}{l}28,000 \\
16,000 \\
14,000 \\
14,000 \\
12,000\end{array}$ & $\begin{array}{l}2,000 \\
2,400 \\
2,400 \\
2,400 \\
2,400\end{array}$ \\
\hline 1 & $\begin{array}{l}1 \\
2 \\
3 \\
4 \\
5\end{array}$ & $\begin{array}{r}190,000 \\
-- \\
30,000 \\
28,000\end{array}$ & $\begin{array}{l}14,000 \\
16,000 \\
12,000 \\
13,000 \\
13,000\end{array}$ & $\begin{array}{r}>400,000 \\
-- \\
50,000 \\
20,000 \\
21,000\end{array}$ & $\begin{array}{l}8,000 \\
6,000 \\
4,800 \\
6,400 \\
6,000\end{array}$ \\
\hline 2 & $\begin{array}{l}1 \\
2 \\
3 \\
4 \\
5\end{array}$ & $\begin{array}{r}210,000 \\
48,000 \\
36,000 \\
30,000 \\
31,000\end{array}$ & $\begin{array}{r}210,000 \\
140,000 \\
99,000 \\
80,000 \\
65,000\end{array}$ & $\begin{array}{r}>400,000 \\
>400,000 \\
320,000 \\
260,000 \\
270,000\end{array}$ & $\begin{array}{r}350,000 \\
200,000 \\
120,000 \\
66,000 \\
47,000\end{array}$ \\
\hline 5 & $\begin{array}{l}1 \\
2 \\
3 \\
4 \\
5\end{array}$ & $\begin{array}{r}230,000 \\
80,000 \\
38,000 \\
34,000\end{array}$ & $\begin{array}{r}330,000 \\
220,000 \\
-- \\
56,000\end{array}$ & $\begin{array}{l}>400,000 \\
>400,000 \\
>400,000 \\
>400,000 \\
>400,000\end{array}$ & $\begin{array}{r}>400,000 \\
>400,000 \\
>400,000 \\
190,000 \\
150,000\end{array}$ \\
\hline 6 & $\begin{array}{l}1 \\
2 \\
3 \\
4 \\
5\end{array}$ & $\begin{array}{l}>400,000 \\
>400,000 \\
>400,000 \\
>400,000 \\
>400,000\end{array}$ & $\begin{array}{l}>400,000 \\
>400,000 \\
>400,000 \\
>400,000 \\
>400,000\end{array}$ & $\begin{array}{l}>400,000 \\
>400,000 \\
>400,000 \\
>400,000 \\
>400,000\end{array}$ & $\begin{array}{l}>400,000 \\
>400,000 \\
>400,000 \\
>400,000 \\
>400,000\end{array}$ \\
\hline & & & itial V & ity $(C P)$ & \\
\hline $\begin{array}{l}0 \\
1 \\
2 \\
5 \\
6\end{array}$ & & $\begin{array}{r}180,000 \\
190,000 \\
210,000 \\
230,000 \\
>400,000\end{array}$ & $\begin{array}{r}7,200 \\
14,000 \\
210,000 \\
330,000 \\
>400,000\end{array}$ & $\begin{array}{r}28,000 \\
>400,000 \\
>400,000 \\
>400,000 \\
>400,000\end{array}$ & $\begin{array}{r}2,000 \\
8,000 \\
350,000 \\
>400,000 \\
>400,000\end{array}$ \\
\hline
\end{tabular}




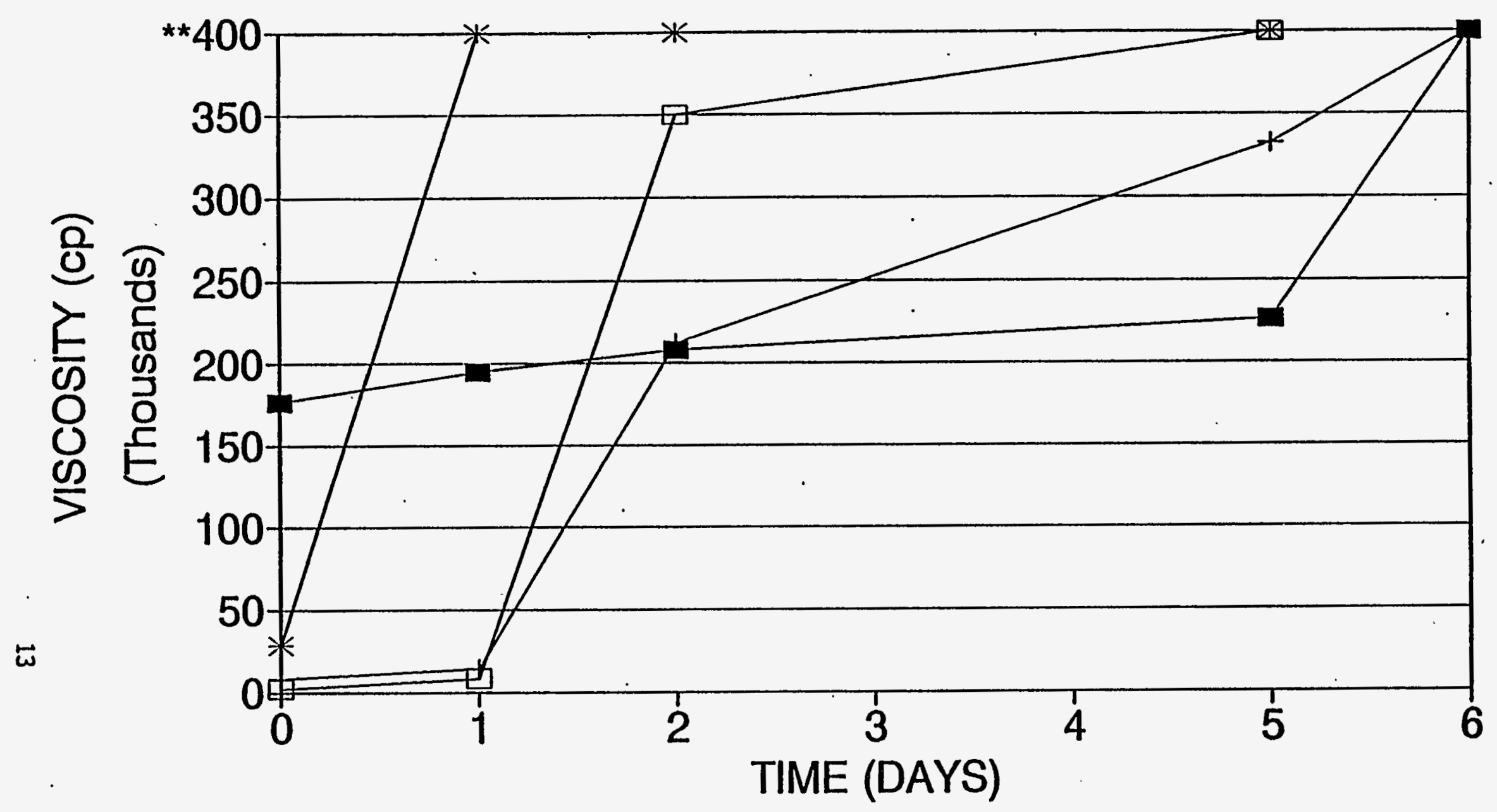

$\rightarrow$ - UNMIXED SMALL + - MIXED SMALL $\rightarrow$ UNMIXED LARGE $\boxminus$ MIXED LARGE

** 400,000 CP was the largest measurable reading.

FIGURE 4.4. Viscosity of Large and Small Silica as a Function of Mixing and Setting Time (based on initial viscosity readings) 
In the WVDP SBS evaluation, it was found that the method used for adding silica to the tank significantly affected the viscosity of the settled silica. Silica added to the tank dry (unmixed silica) resulted in a sediment that exhibited a much higher viscosity than silica added to the tank as a wellmixed slurry (Figure 4.4). The fully mixed slurry provided a less viscous sediment for resuspension that is more representative of the actual SBS sediment since the particulate capture mechanisms within the SBS generate a sediment composed of thoroughly wetted particles. After $48 \mathrm{~h}$, the silica in the fully mixed sample apparently consolidated enough to greatly increase the sediment viscosity. This change indicates that the sparge rings in the SBS should be operated at least every $24 \mathrm{~h}$ to prevent substantial consolidation of the accumulated sediment, if the actual sediment behaves similarly to the tested silica. The sample size from the SBS collected from PSCM-23 was not sufficient for viscosity determinations. Sufficient quantities of actual sediment should be collected during the next melter run to allow for determinations of sediment rheological properties.

The silica in the test stand was mixed and uniformly distributed across the tank bottom prior to each run to provide a consistent baseline and comparable data. For the sediment resuspension testing, the silica was never allowed to settle for more than $24 \mathrm{~h}$ prior to a run. As can be seen from the viscosity data tabulated in Table 4.2 and plotted in Figure 4.4 , the viscosity for fully mixed silica was essentially constant for the first. $24 \mathrm{~h}$ of settling time.

The silica density was determined in order to calculate the weight percent silica concentration in the test tank. Heighed quantities of silica powder and water were mixed in a graduated cylinder, and the total volume of the slurry was determined. The total volume, silica and water weight, and fluid volume were used to calculate the silica volume. [The sample size from the SBS collected from PSCM-23 was not sufficient for a density determination.] The particle densities for the large and small silica powders were as follows:

$\begin{array}{ll}\text { Material } & \text { Density } \\ \text { Small Silica } & 2.42 \mathrm{~g} / \mathrm{mL} \\ \text { Large Silica } & 2.64 \mathrm{~g} / \mathrm{mL}\end{array}$




\subsection{EXPERIMENTAL APPROACH}

\subsection{JET PATTERNS WITH TRACER PARTICLES}

The jet patterns and relative cleaning areas at the three tested water flow rates were examined by introducing metal tracer particles (approximately $1 \mathrm{~mm} \times 1 \mathrm{~mm} \times 0.1 \mathrm{~mm}$ ) into the tank. The tracer particle testing was done to provide a qualitative indication of the behavior of the sparge jets. Cleaning areas (the areas on the bottom of the tank swept clean of metallic particles) were mapped-out through visual observations of the tracer particles movement in the tank after several min ( 3 to $5 \mathrm{~min}$ ) of sparge operation. Because the size and density of the metallic particles differ from silica and actual sediment, no attempts were made to extrapolate the cleaning pattern data obtained from the metallic particles to other systems.

\subsection{SILICA RESUSPENSION TESTING}

For each set of tests, a known quantity. of silica (approximately $16 \mathrm{~kg}$ ) was added to the tank in the form of a well-mixed slurry. Water was added to the tank to achieve a liquid depth of approximately 20 in. The temperature of the water during testing was approximately $25^{\circ} \mathrm{C}$. The silica formed $\dot{a}$ sediment layer approximately $1 \mathrm{in}$. in depth after being allowed to settle for $24 \mathrm{~h}$. During jet operation, samples of slurry were taken, filtered, and oven dried at approximately $80^{\circ} \mathrm{C}$. The weight of dry silica in the samples was determined and compared with the ideal uniform silica concentration if all silica in the test tank had been resuspended (6.0\% to $6.3 \%$ - for this testing).

Resuspension testing with settled silica (see Section 4.3 for silica property data) was performed at sparge flow rates of $1,2.1$, and $3 \mathrm{gpm}$ per placement. These flow rates correspond to total flow rates in the HWV sparge of 24,50 , and $72 \mathrm{gpm}$. During the resuspension testing, measurements of silica concentration and visual observations were made to determine the effectiveness of the sparge. (The testing matrix is provided in Appendix B.) The quantity of silica resuspended was determined by measuring the silica concentration in the tank at various sparge operating times and sparge flow 
rates. From beneath the test stand tank, observations were made and measurements were taken to quantify the size of the clean areas.

From the WVDP SBS evaluation testing conducted in May 1991, it was found that the silica addition method and the settling time had a significant impact on the settled silica viscosity. The viscosity data indicated that after approximately $48 \mathrm{~h}$ of settling time, the viscosity of the settled silica increased drastically. During the first $24 . h$ of settling time, the viscosity remained essentially constant. To ensure that data from each run performed for the HWVP SBS sedimentation testing was comparable, the silica was initially added to the tank in a slurry. Prior to each run, the silica was thoroughly mixed ( 6 to $24 \mathrm{~h}$ prior to testing) to uniformly distribute the silica across the tank bottom. 


\subsection{RESULTS}

The SBS sparge ring and tank bottom _can be visualized as twenty-four $15^{\circ}$ sectors with four perforations on the sparge ring to clean each sector. Figure 6.1 shows the areas on the tank bottom swept clean of metal particles (i.e., effective cleaning area) at flow rates of 1, 2.1, and $3 \mathrm{gpm}$ with an overlay of the $15^{\circ}$ sector for reference.

Figure 6.1 indicates that jets from the perforations in one $15^{\circ}$ sector will influence the adjacent sectors (i.e., the areas on the tank bottom swept clean of tracer particles extended beyond the boundary of the $15^{\circ}$ sector). Additionally, the vertically downward directed jet influences a greater area than any of the other jets. This influence is believed to be an artifact of the distances the jets must penetrate through the liquid prior to reaching the tank bottom. The downward directed jet must travel through 8 in. of liquid to reach the tank bottom. This distance is considerably less than the travel distance of the jets from the $70^{\circ}$ perforation (25 in.) or of the jet from the $55^{\circ}$ perforation (15 in.).

Because the size, geometry, and density of the tracer particles differ greatly from that of PSCM-SBS sediment particles, it is not possible to extrapolate the results depicted in Figure 6.1 to the performance of the sparge ring in the actual. HWVP SBS. Consequently, Figure 6.1 should only be used to gain an understanding of what areas are influenced by the jets.

The silica concentrations at various sampling locations and depths, along with the sizes of the cleaned areas after $1 \mathrm{~h}$ of jet operation, are reported in Table-6.1. Two values for percent clean area are reported in Table 6.1. One is based on the total area of the bottom of the test tank, and the other is based on the area of the area of the bottom of the tank inside the $15^{\circ}$ sector overlay.

Two sets of runs were performed for each of the two size classifications of silica. After the first set of runs were completed, it was found that the perforation directed toward the center of the tank was partially plugged by a piece of plastic and sediment that had accumulated inside the sparge section. Consequentiy, a second set of runs was performed. Where there is a discrepancy in data between the two runs, data from the second set of runs should be assumed to be more accurate. 
Ke L Lano

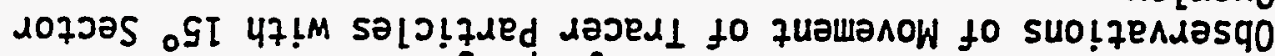

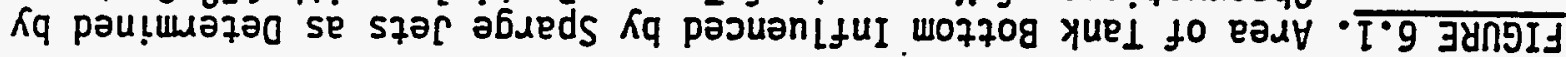

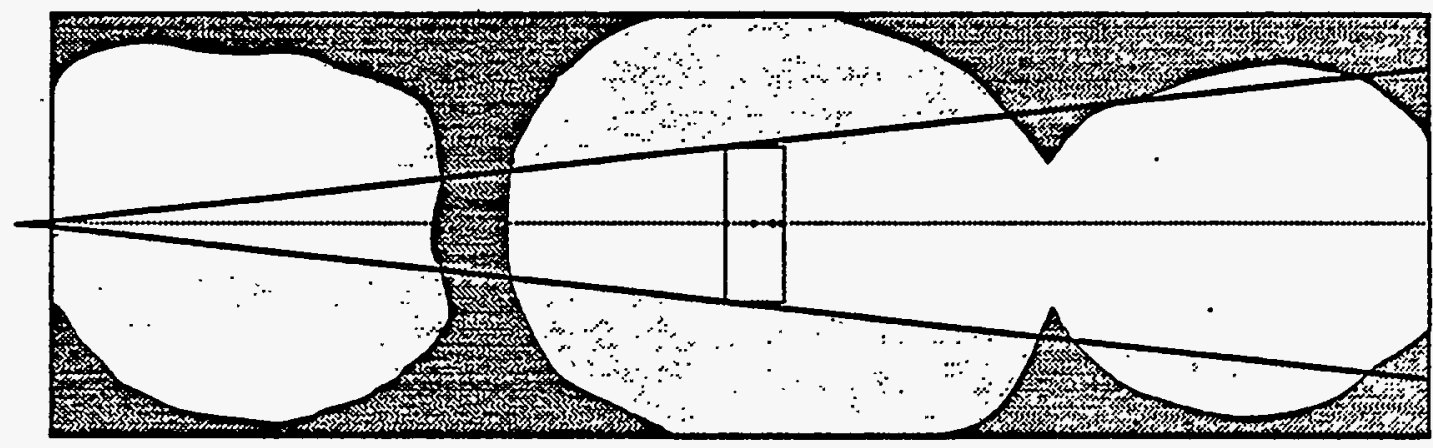

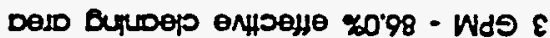

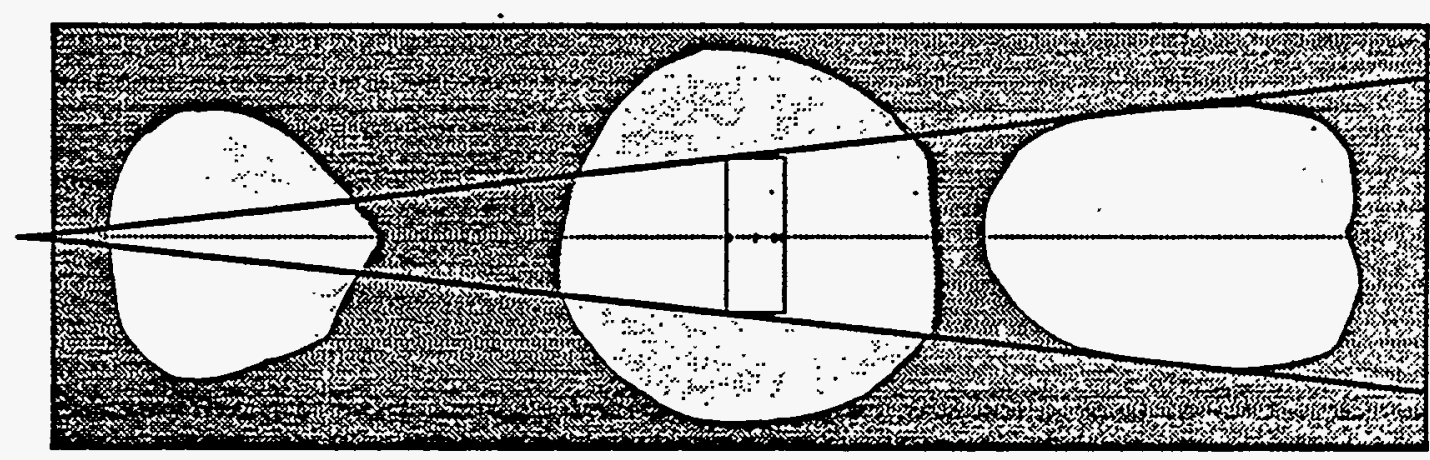

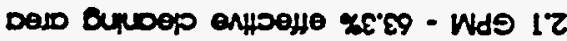

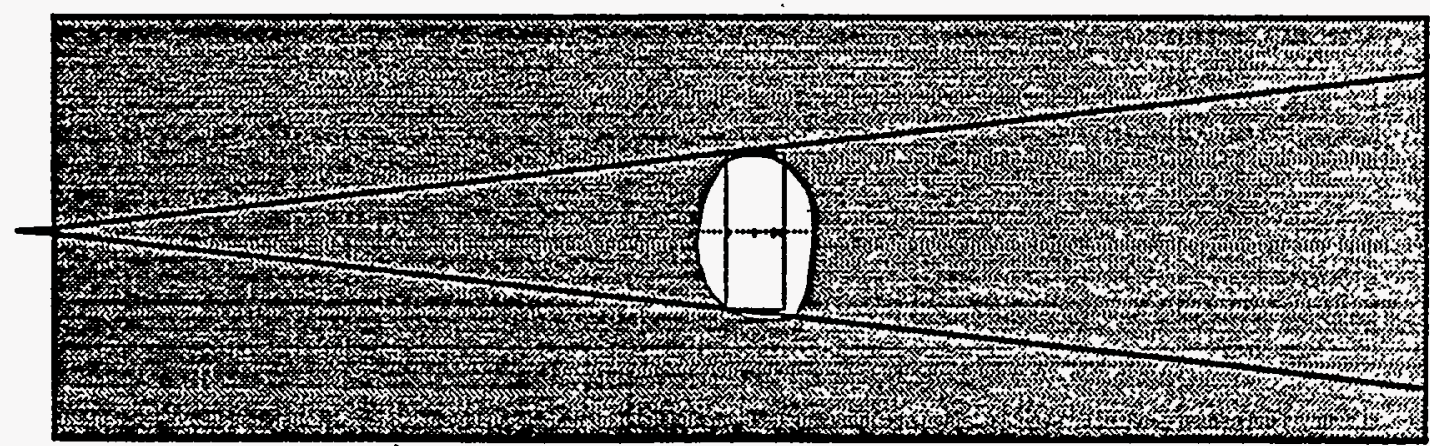

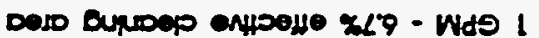


TABLE 6.1. Tabular Results of Resuspension Testing

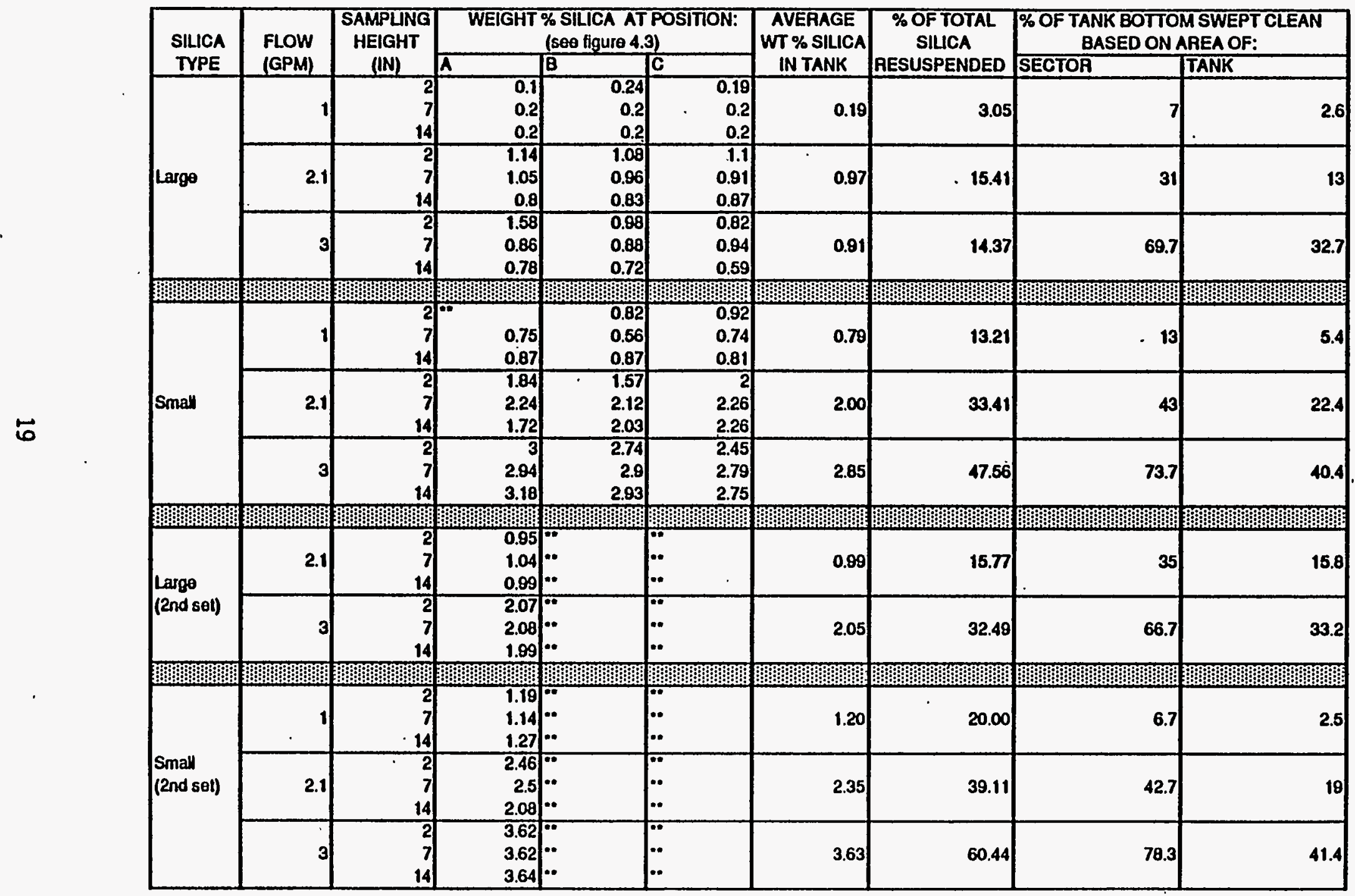


The data in Table 6.1 indicate that at the design flow rate $(2.1 \mathrm{gpm}$ per hole set--50 gpm total sparge ring), only about $40 \%$ of the settled sediment (small silica) can be expected to be resuspended. The actual amount of sediment resuspension that can be achieved in the HWVP SBS will probably be greater as a result of additional eddy currents and turbulence caused by adjacent jet interaction. Additionally, some of the resuspended sediment in the test tank may have settled in quiescent areas that may have been artifacts of the test tank geometry. At higher flow rates, better resuspension can be realized; however, modifications of the sparge ring configuration could probably result in better sparge ring performance without increasing the flow rate. This option may be preferable since increasing the flow rate will potentially increase, the production of wastewater.

Figures 6.2 and 6.3 have been prepared to facilitate the visualization of the data in Table 6.1. Figure 6.2 shows the cleaning areas at various flow rates with the large silica sediment after 10,30, and $60 \mathrm{~min}$ of jet operation. Figure 6.3 shows the cleaning areas observed with the smaller sediment. The maximum effective cleaning areas shown in text on these figures were calculated based on the areas within the $15^{\circ}$ sectors after a 60 min period of sparge operation. The size of the clean areas continued to increase during the first 30 min of sparge operation; however, the concentration of silica in the test stand tank remained relatively constant after about 10 min of sparge operation. This agrees with the results obtained from the WVDP SBS evaluation, which utilized a different sparge configuration. During the WVDP SBS evaluation, it was found that the silica concentration remained essentially constant after 5 min of operation with water as the motive jet fluid.

Figure 6.4 shows the relationship between sediment resuspension and the effective cleaning area for the two classifications of silica with values on a total tank basis. For the large silica, the relationship is essentially a 1to-1 correspondence that goes through the origin. This indicates that with the large silica, only the cleaned area is influenced by the jet (i.e., areas outside the clean area probably are not influenced by the jet). With the small silica, the percentage of silica resuspended was greater than the percentage of area swept clean of silica on the tank bottom. This indicates that the jets from the 
1 GPM - 7.06 effective clecing creo

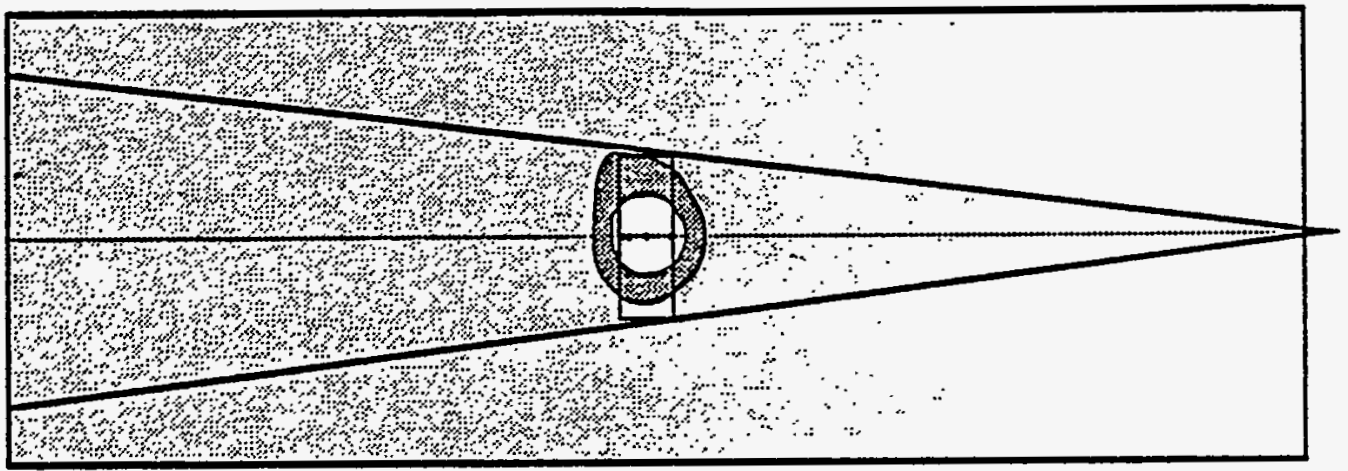

21 GPM - 35.0\% effective cleaning areo

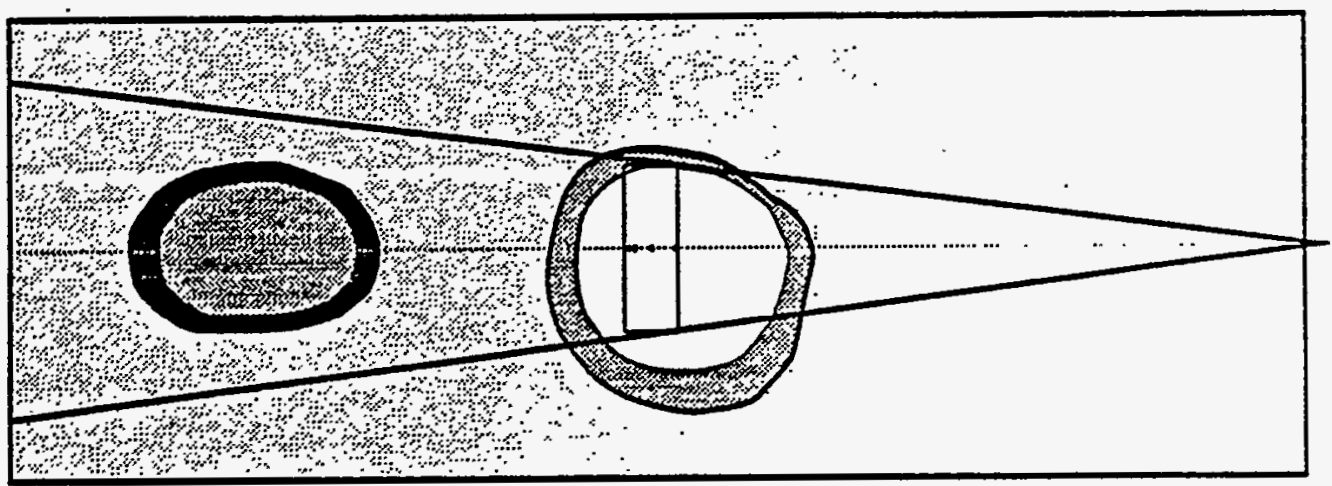

$3.0 \mathrm{GPM}-66.7 \%$ effective cloaning areo
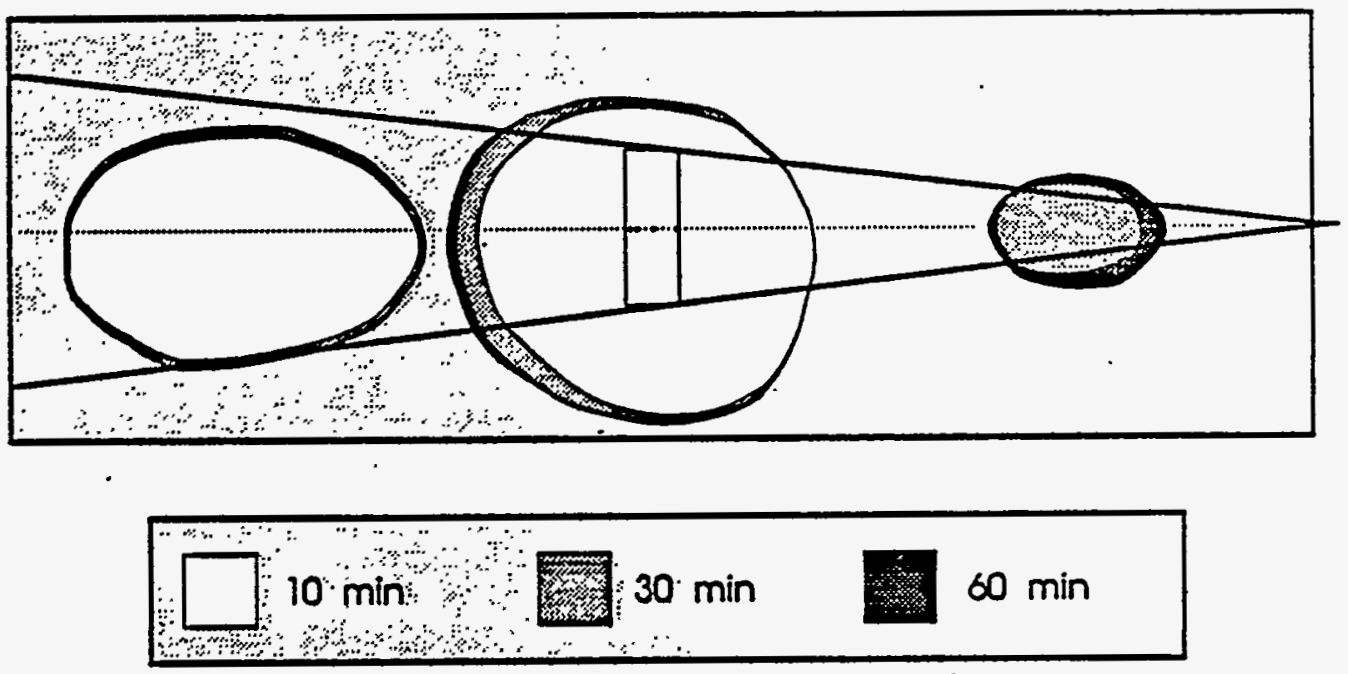

FIGURE 6.2. Area of Tank Bottom Cleaned of Large Silica with $15^{\circ}$ Sector Overlay after $10 \mathrm{Min}, 30 \mathrm{Min}$, and 60 Min of Sparging [Note: $1 \mathrm{gpm}$ from first data set; 2.1 and $3 \mathrm{gpm}$, from second data set] 


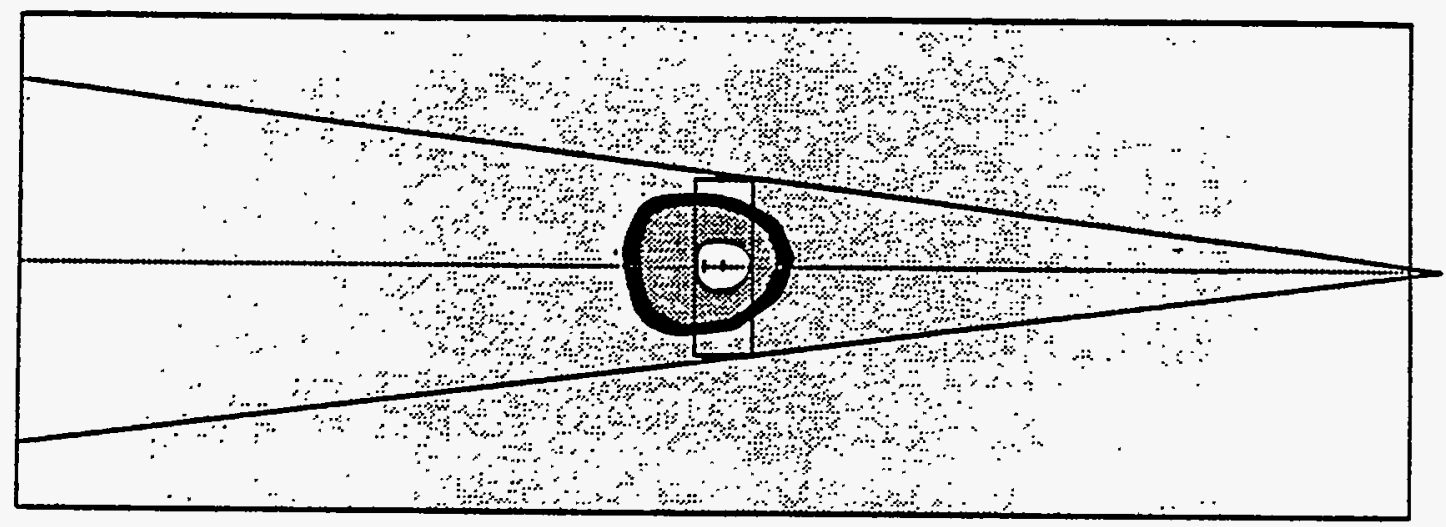

2.1 GPM: 42.7\% effective clearing area

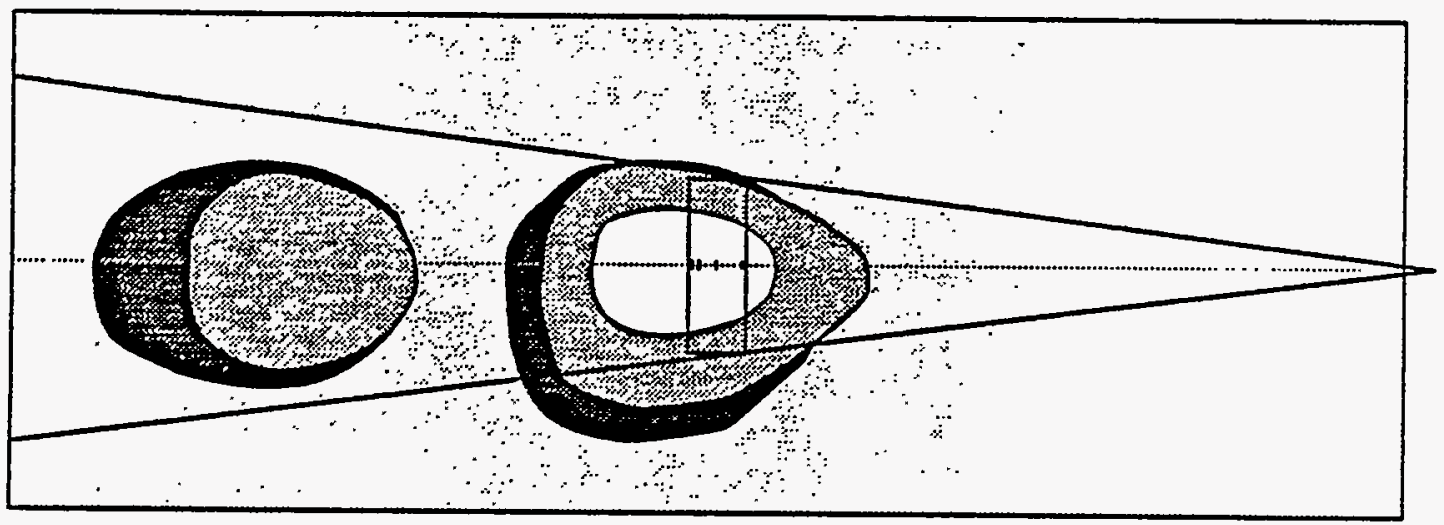

3.0 GPM: 78.3\% effective cleaning areo
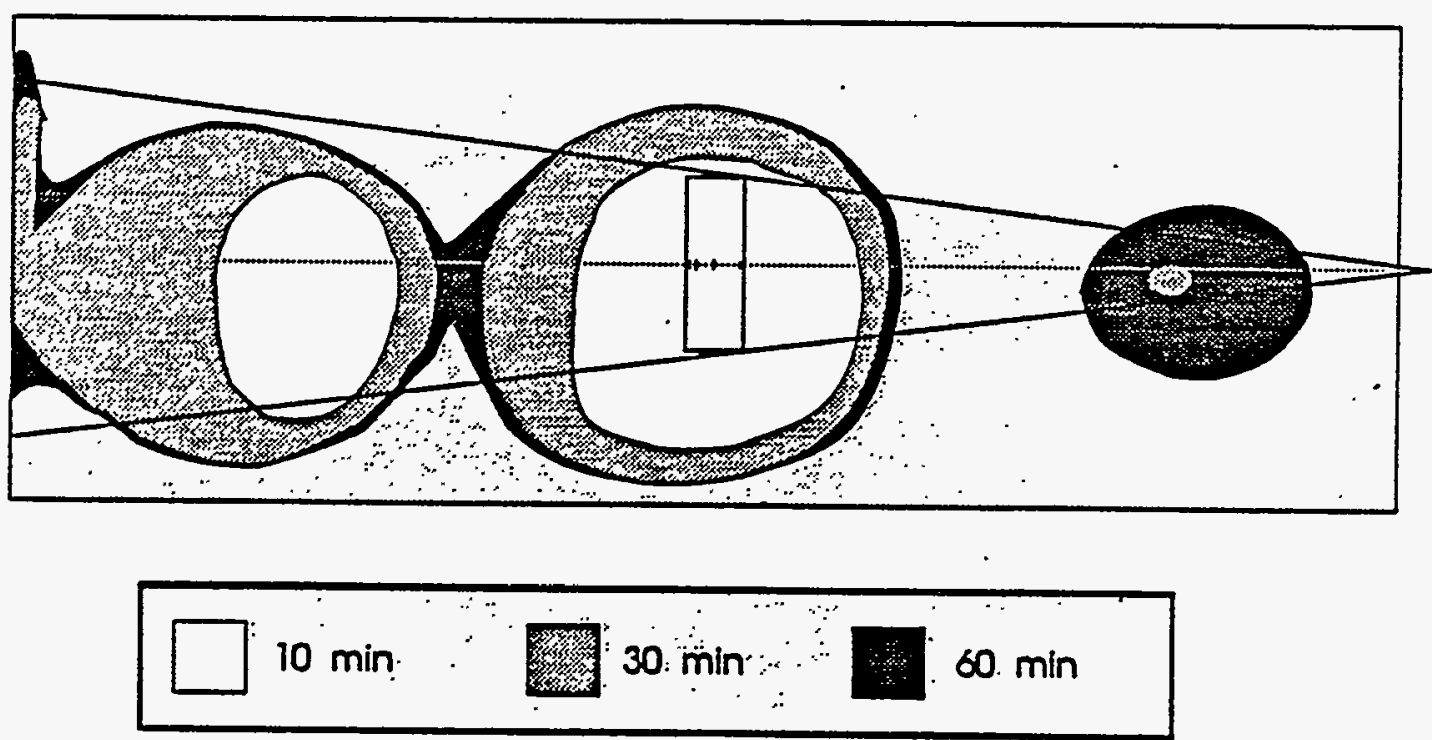

FIGURE 6.3. Area of Tank Bottom Cleaned of Small Silica with $15^{\circ}$ Sector Overlay after $10 \mathrm{Min}, 20 \mathrm{Min}$, and 60 Min of Sparging [Note: all data taken from second data set] 


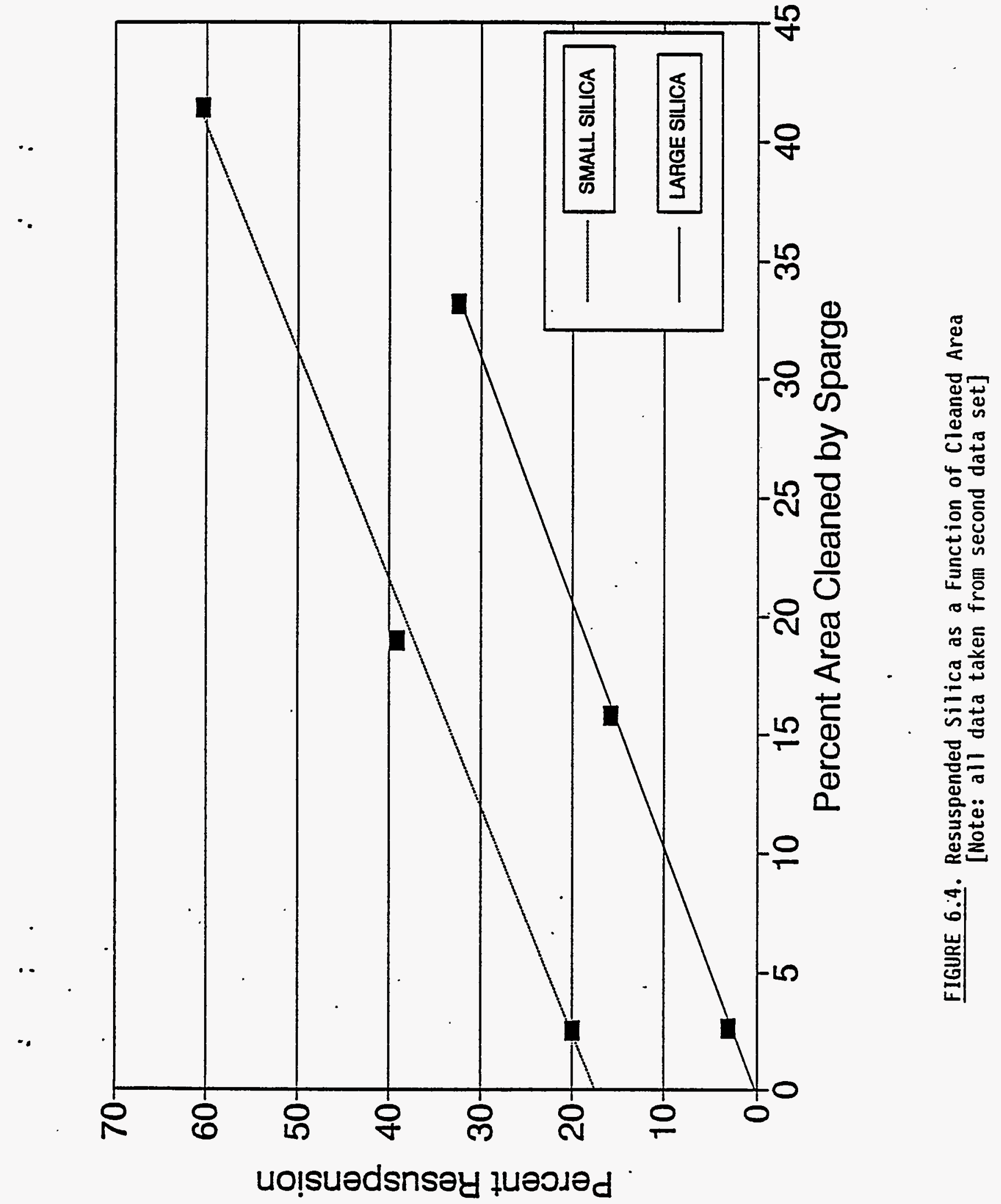


sparge affected sediment outside the cleaning area. The difference in behavior of the two classifications of silica may be attributed to the lower settling velocity associated with the smaller silica. With the larger silica, resuspended particles may be settling in quiescent areas within the tank.

Figure 6.5 has been prepared to assist in visualizing the areas in the HWVP SBS tank bottom that are projected to be swept clean of sediment (provided that actual sediment behaves similarly to the tested silica). Figure 6.5 shows the experimentally determined cleaning.areas with the large and small silica overlaid onto a plan-view of the bottom of the HWVP SBS. This figure provides indications of where jet interaction and sediment accumulation are expected to occur. Figure 6.5 also indicates that the overall performance of the sparge at the HWVP design flow rate of $2.1 \mathrm{gpm}$ per placement (50 gpm--entire ring) will be marginal for effective cleaning. 


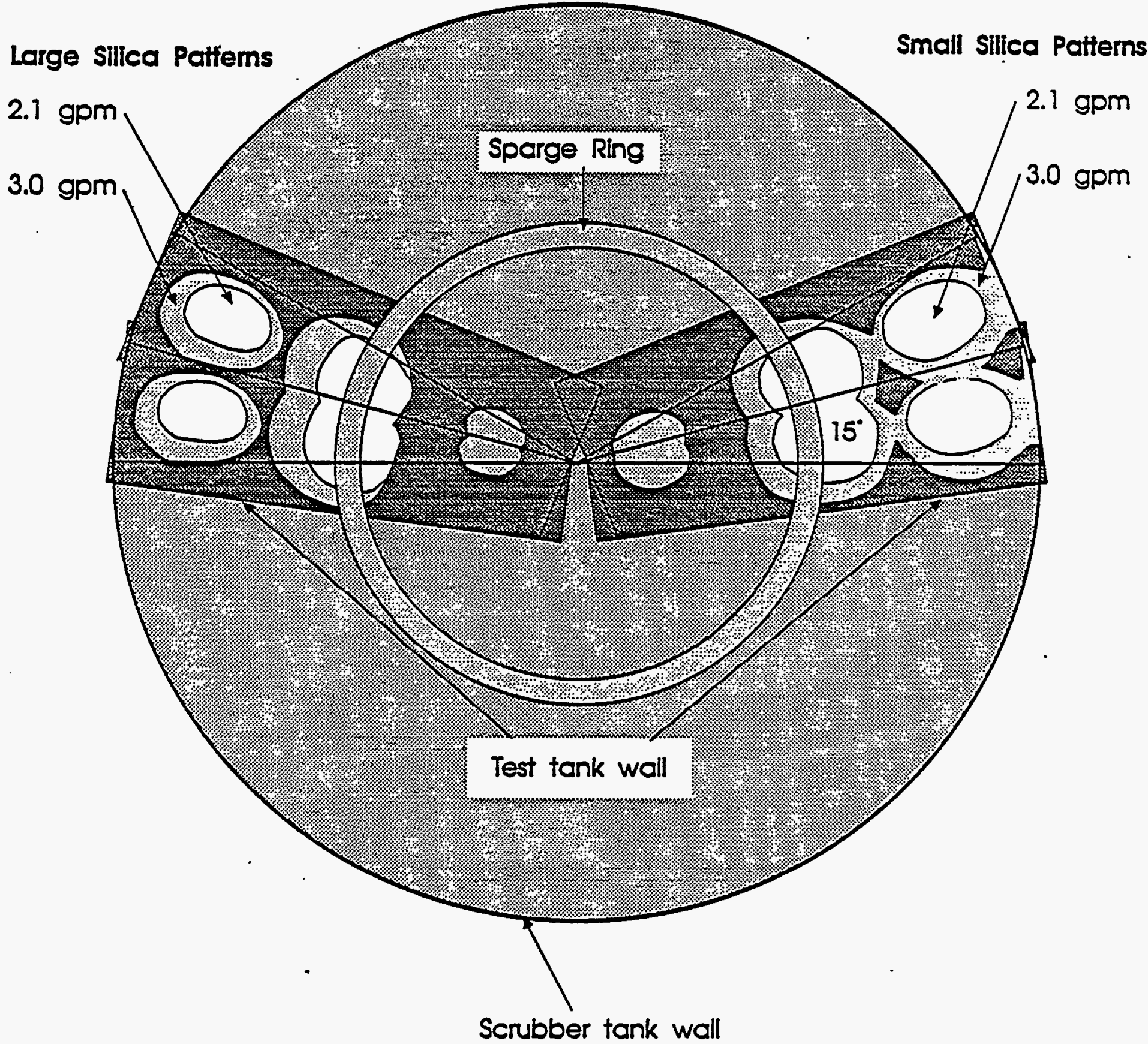

FIGURE 6.5. Overlay of Cleaning Areas (after 60 Min of Sparge Operation) onto Plan-View of HWVP SBS. 
APPENDIX A

OPTICAL ANALYSES PARTICLE SIZE DISTRIBUTION

DATA FOR SILICA AND PSCM-23 SBS SEDIMENT 


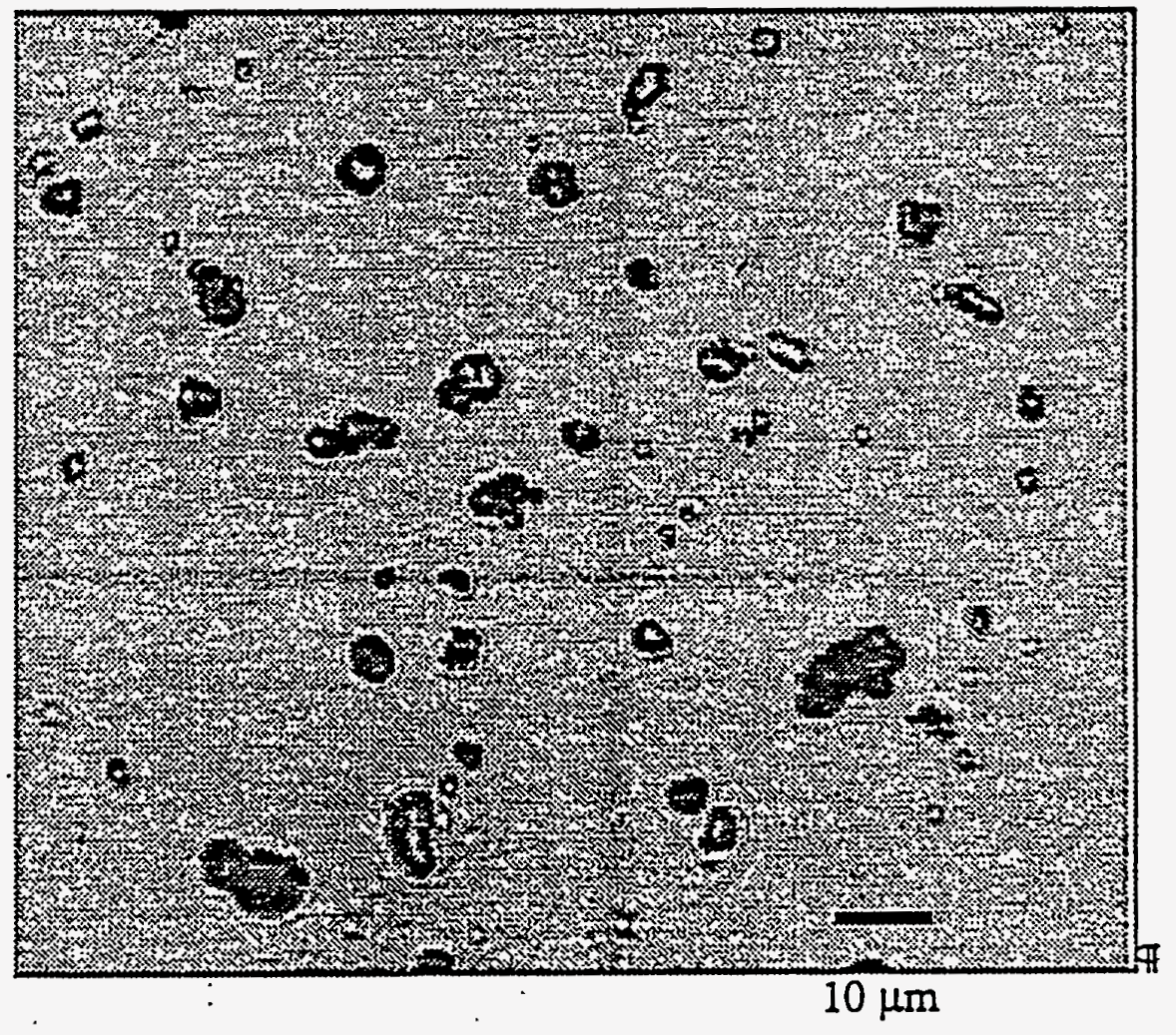

\begin{tabular}{|c|c|c|c|c|c|}
\hline Mean: & Std. Dev.: & $\begin{array}{l}X_{1}: \text { Eq } \\
\text { Std. Error: }\end{array}$ & $\begin{array}{l}\text { Dlam. }(\mu \mathrm{m}) \\
\text { Variance: }\end{array}$ & Coof. Var: & Count: \\
\hline 3.1388 & 2.9879 & .1716 & 8.9274 & 95.1909 & 303 \\
\hline Minimum: & Maximum: & Range: & Sum: & Sum of Sar: & \# Missing: \\
\hline .2793 & 16.8926 & 16.6133 & 951.0623 & 5681.2801 & 0 \\
\hline$\#<10$ th $\%:$ & 10th \%: & 25th \%: & 50th \%: & 75th $\%:$ & goth \%: \\
\hline 23 & .395 & .9675 & 2.1814 & 4.5014 & 6.8196 \\
\hline \multicolumn{6}{|l|}{$\#>$ 90th \%: } \\
\hline 30 & & & & & \\
\hline
\end{tabular}

FIGURE A.1. Particle Size Properties of Large Silica

A.1 

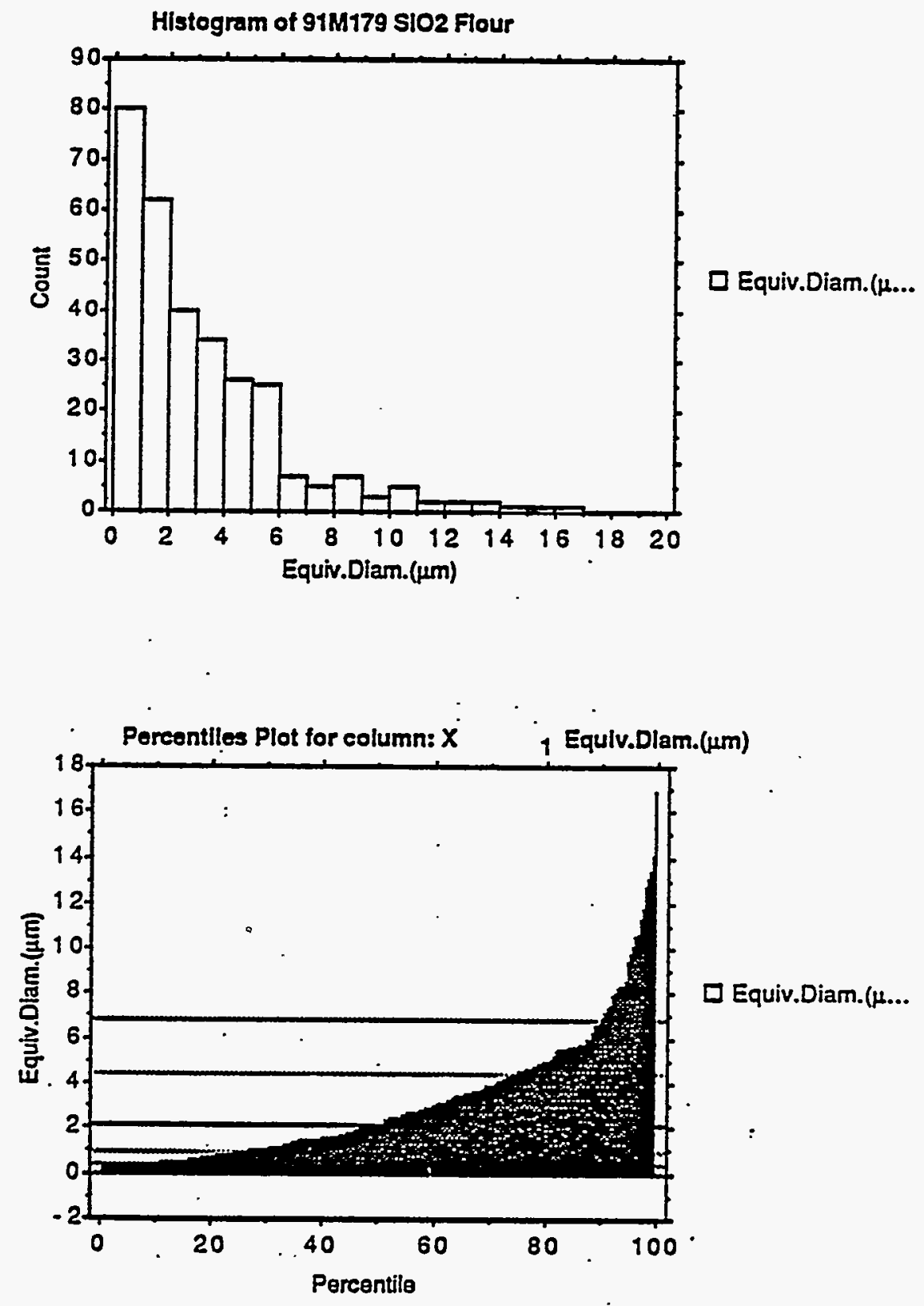

FIGURE A.2. Particle Size Distribution of Large Silica

A.2 


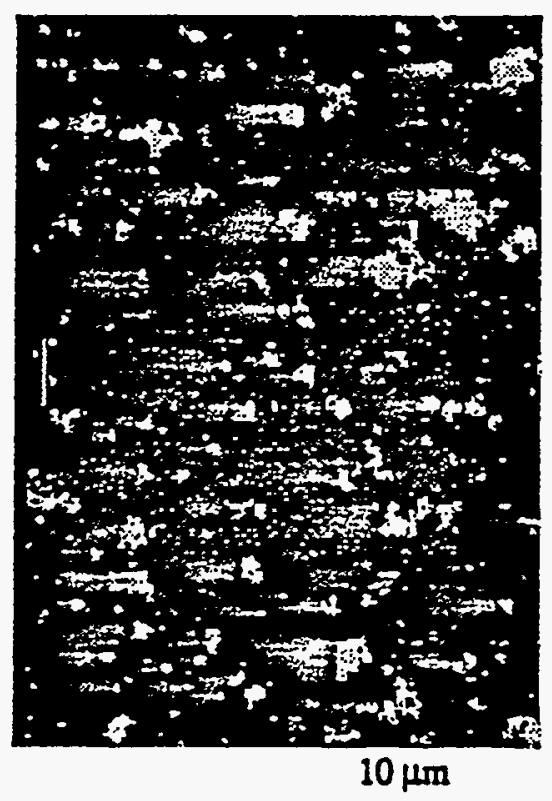

\begin{tabular}{l|l|l|l|l|l|}
\hline & & & & \\
Mean: & Std. Dev.: & Std. Efror: & Variance: & Coof. Var.: & Count: \\
\hline 1.462 & 1.572 & .059 & 2.473 & 107.551 & 717 \\
\hline Minimum: & Maximum: & Range: & Sum: & Sum of Sgr:: \# Missing: \\
\hline .138 & 13.147 & 13.009 & 1048.312 & 3303.169 & 0 \\
\hline
\end{tabular}

$X_{1}$ : Roundness

\begin{tabular}{l|l|l|l|l|l|} 
Mean: & Std. Dev.: & Sid. Error: & Variance: & Coef. Var.: & Count: \\
\hline .361 & .088 & .003 & .008 & 24.436 & 717 \\
\hline Minimum: & Maximum: & Range: & Sum: & Sum of Sgr.: \# Missing: \\
\hline .092 & .704 & .612 & 258.91 & 99.068 & 0 \\
\hline
\end{tabular}

\begin{tabular}{|c|c|c|c|c|c|}
\hline Moan: & Std. Dev.: & Std. Error: & Varianeo: & Cool. Var.: & Count: \\
\hline 1.791 & .58 & .022 & .337 & 32.386 & 717 \\
\hline Minimum: & Maximum: & Range: & Sum: & Sum of Sar: & \# Missing: \\
\hline 1.079 & 9.022 . & 7.942 & 1284.414 & 2541.862 & 0 \\
\hline
\end{tabular}

\section{FIGURE A.3. Particle Size Properties of Small Silica}




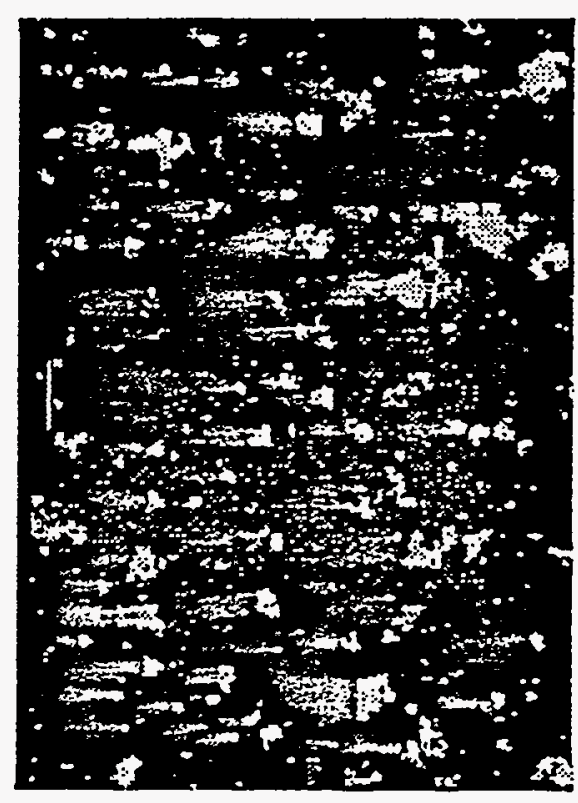

$X_{1}$ : Equiv.Dlam.(um)

\begin{tabular}{|c|c|c|c|c|}
\hline Bar: & From: (Z) & To: $(<)$ & Count: & Percent: \\
\hline 1 & .138 & 1.539 & 500 & $69.735 \%$ \\
\hline 2 & 1.539 & 2.939 & 130 & $18.131 \%$ \\
\hline 3 & 2.939 & 4.34 & 50 & $6.974 \%$ \\
\hline 4 & 4.34 & 5.741 & 16 & $2.232 \%$ \\
\hline 5 & 5.741 & 7.142 & 10 & $1.395 \%$ \\
\hline 6 & 7.142 & 8.543 & 6 & $.837 \%$ \\
\hline 7 & 8.543 & 9.944: & 1 & $.139 \%$ \\
\hline 8 & 9.944 & 11.345 & 2 & $.279 \%$ \\
\hline 9 & 11.345 & 12.746 & 1 & $.139 \%$ \\
\hline 10 & 12.746 & 14.147 & 1 & $.139 \%$ \\
\hline
\end{tabular}

Equivalent Diameter is the diameter of a circle with the same area as the feature

FIGURE A.4. Particle Size Distribution of Small Silica 


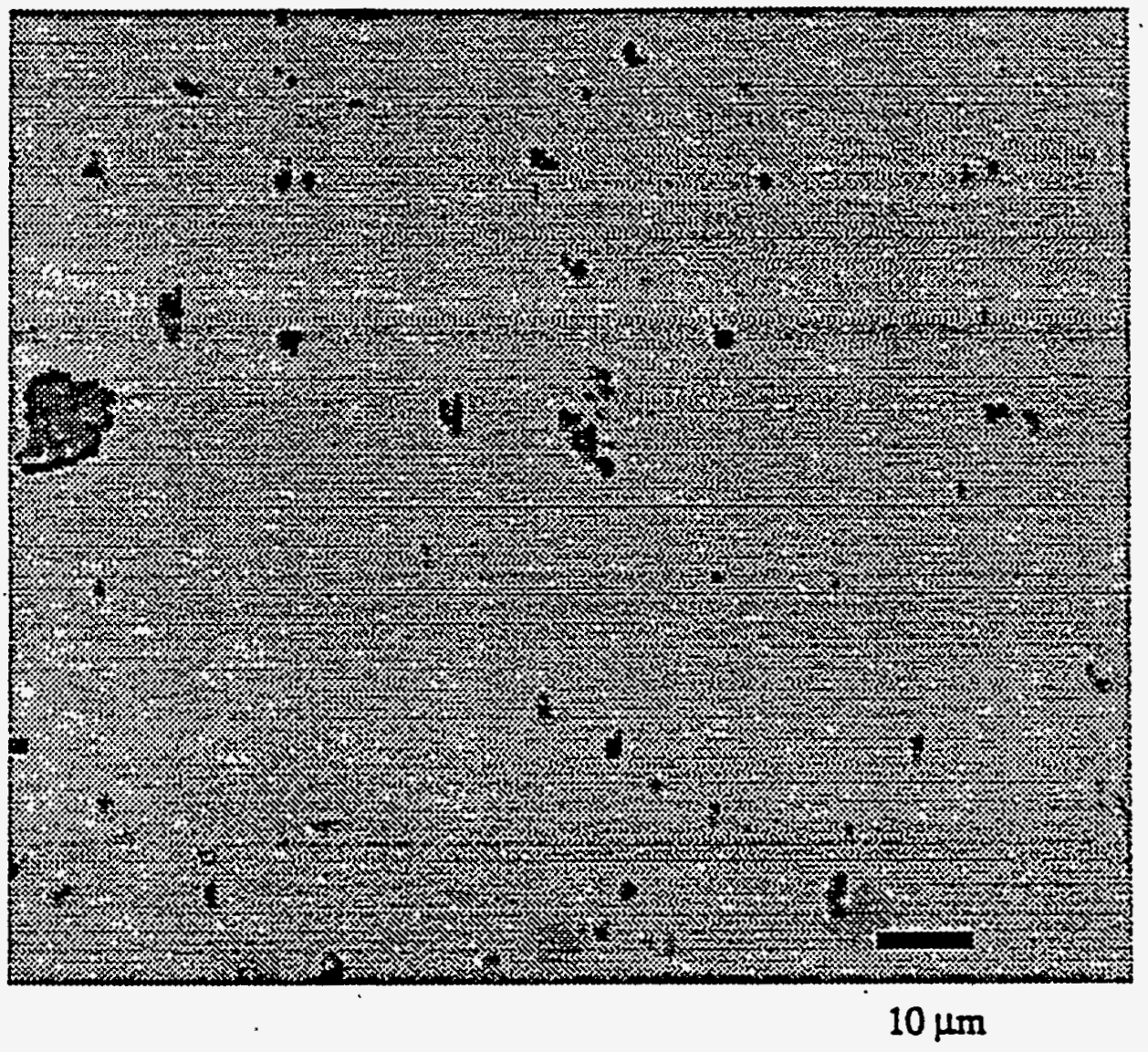

\begin{tabular}{|c|c|c|c|c|c|}
\hline \multirow[b]{2}{*}{ Mean: } & \multicolumn{3}{|c|}{$X_{1}$ : Equlv.Dlam. $(\mu m)$} & \multirow[b]{2}{*}{ Coof. Var.: } & \multirow[b]{2}{*}{ Count: } \\
\hline & Std. Dev.: & Std. Error: & Variance: & & \\
\hline 1.55 & 1.68 & .242 & 2.822 & 108.394 & 48 \\
\hline Minimum: & Maximum: & Range: & Sum: & Sum of Sgr.: & \# Missing: \\
\hline .279 & 11.287 & 11.007 & 74.389 & 247.914 & 0 \\
\hline$\#<10$ th \%: & 10th \%: & 25th \%: & 50th \%: & 75th \%: & 9oth \%: \\
\hline 4 & .395 & .521 & 1.248 & 1.945 & 2.671 \\
\hline
\end{tabular}

\# > 90th \%:

5

FIGURE A.5. Particle Size Properties from PSCM-23 SBS Sediment Collected in 1988 
$X_{1}:$ Equiv.Dlam.(um)

\begin{tabular}{|c|c|c|c|c|}
\hline Bar: & From: (2) & To: $(<)$ & Count: & Percent: \\
\hline 1 & .279 & 1.48 & 28 & $58.333 \%$ \\
\hline 2 & 1.48 & 2.681 & 15 & $31.25 \%$ \\
\hline 3 & 2.681 & 3.882 & 4 & $8.333 \%$ \\
\hline 4 & 3.882 & 5.082 & 0 & $0 \%$ \\
\hline 5 & 5.082 & 6.283 & 0 & $0 \%$ \\
\hline 6 & 6.283 & 7.484 & 0 & $0 \%$ \\
\hline 7 & 7.484 & 8.684 & 0 & $0 \%$ \\
\hline 8 & 8.684 & 9.885 & 0 & $0 \%$ \\
\hline 9 & 9.885 & 11.086 & 0 & $0 \%$ \\
\hline 10 & 11.086 & i2.287 & 1 & $2.083 \%$ \\
\hline
\end{tabular}

FIGURE A.6. Particle Size Data from PSCM-23 SBS Sediment Collected in 1988

A. 6 


\section{APPENDIX B}

PROCEDURES FOR SEDIMENT RESUSPENSION TESTING 


\section{PROCEDURES FOR SEDIMENT RESUSPENSION TESTING \\ FOR \\ EVALUATION OF SEDIMENTATION \\ BUILD-UP IN THE HWVP \\ SUBMERGED BED SCRUBBER}

JUNE 1991

PACIFIC NORTHWEST LABORATORY

P. O. BOX 999

RICHLAND WASHINGTON 99352 


\section{PROCEDURES FOR SEDIMENT RESUSPENSION TESTING}

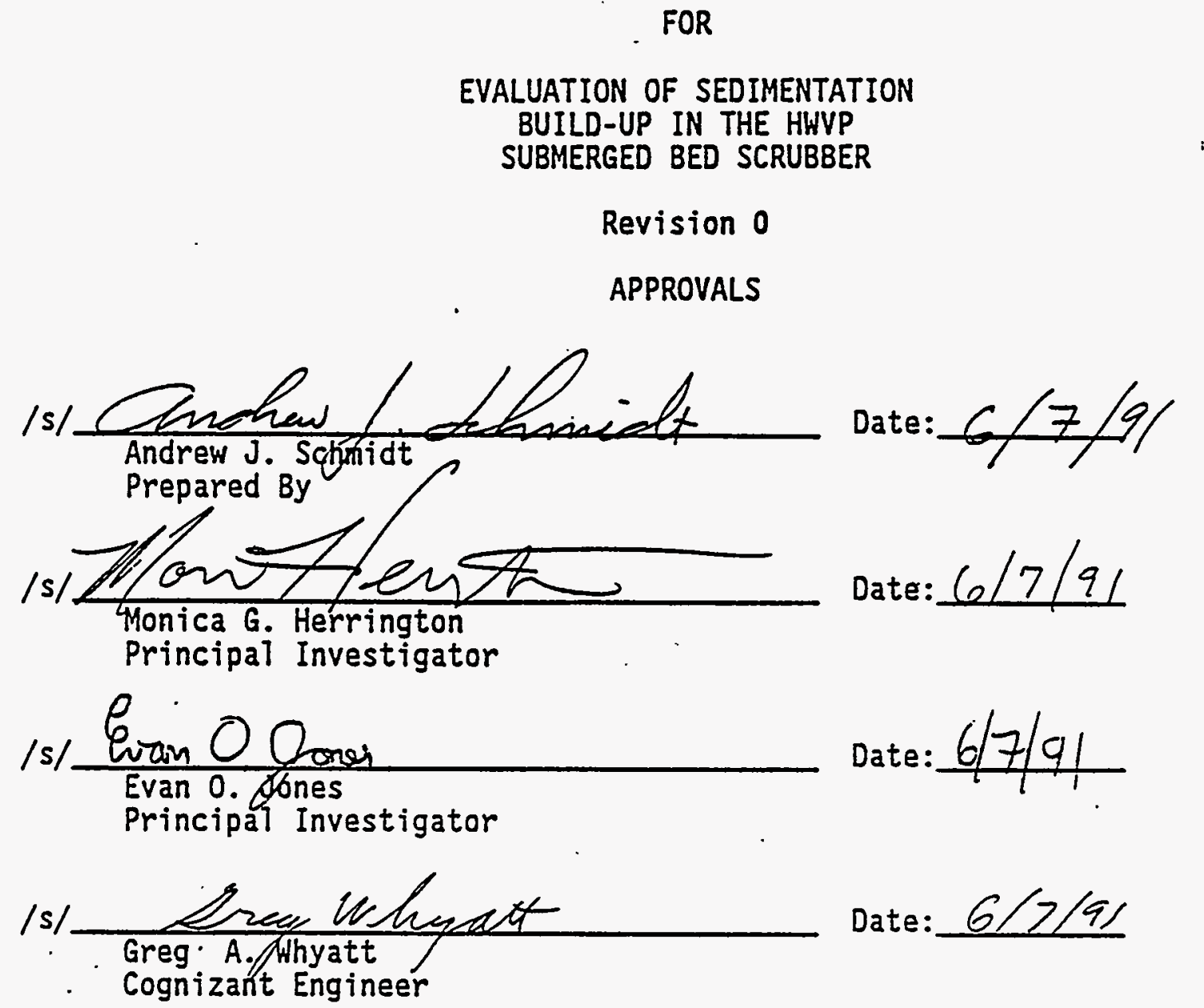




\subsection{Background and Testing Objectives}

As described in the "Test Plan for Performance Evaluation of the LiquidFed Ceramic Meiter (LFCM) Submerged Bed Scrubber (SBS)" (WTC-006-25-3) heretofore referred to as the "test plan", the purpose of the resuspension testing is to evaluated the ability of the sparge ring to resuspend settled solids in the bottom of the.SBS. This objective will be accomplished with a perforated pipe section that simulates a 6 in long section of the HWVP SBS sparge ring. The pipe section will be set up in a glass tank physical model in a configuration analogous to that in the HWVP sparge ring design. Visual observation (including photographs) and measurements will be made to determine the sparge/jet pattern and the effective sparge/jet cleaning distance.

The HWVP SBS design (MOG Submerged Bed Scrubber, SC-14A-001, Rev. 00, 10-16-89) specifies a $4 \mathrm{ft}$ diameter sparge ring $\mathrm{p} 7$ ace concentrically within the $8 \mathrm{ft}$ diameter scrub tank. The sparge ring is a 2 inch diameter, schedule 40 pipe with 24 sets of $3 / 32$-in. holes, with 4 hole per set. The hole sets are uniformly spaced on the ring at $15^{\circ}$ arcs. On the sparge ring, there are a total of $963 / 32$-inch perforations

In accordance with Fluor Daniel Technology Data Needs Item 3.2d, the liquid flow rate to the HWVP sparger developed in the Preliminary Design was originally $25 \mathrm{gpm}$. However, it was determined that $25 \mathrm{gpm}$ is not adequate to maintain the scrub tank level when the scrub tank is being jetted out for sol.ids removal. Solids removal from the scrub tank is currently planned for normal operation when the off-gas flows to the MOG System. Allowing the level to drop would interfere with the melter pressure control. As a result, the design sparge flow rate has been increased to $50 \mathrm{gpm}$. The pressure drop through the holes on the sparger are expected to be approximately 10 psi.

With the physical model, one set of holes (4 perforations) will be examined. The nominal water flow rate to this set of perforations is approximately $2.1 \mathrm{gpm}$ - based on a nominal flow. rate of $50 \mathrm{gpm}$ for the entire sparge ring. At this flow rate the liquid velocity through the perforations will be approximately $25 \mathrm{ft} / \mathrm{sec}$.

This document describes the equipment and procedures that will be used to evaluate the HWVP SBS sparge ring design with respect to resuspending sedimentation. 


\subsection{OVERVIEN OF TESTING}

A single full-scale 6 inch-section of the sparge ring will be tested in a clear glass tank to determine the jet pattern and the effective jet cleaning area. The data from this testing will be evaluated with respect to the SBS geometry. Testing will be initiated with water as the motive fluid. Silica flour will be used to simulate SBS sediments for the initial testing.

The tank homogeneity will be determined by visual observation and measuring the wt\% solids at various elevations and radial distances. Descriptions and photography will be used to document visual results. The slurry samples will be pulled with a sampling manifold and filtered. The collected solids will be dried and weighed to obtain a profile of the solids concentration within the single jet tank.

Observations during test runs previous to SF-12 indicated that minor quantities of sediment build-up in the SBS that occurred, tended to accumulate around the bottom perimeter. Thus, the resuspension evaluation with a sparger section containing a set of $43 / 32$ holes will focus upon the outer sparge ring geometry. 


\subsection{MATERIALS AND EQUIPMENT}

The test stand consists of a 90 gallon glass tank supported by a unistrut framework (see Figure 1). A 6-inch 1ong, 2-inch schedule 40 pipe section was fabricated to replicate one of the a section of the HWVP sparge ring (see figure 2). The perforated pipe section is connected to a water supply line equipped with a pressure gage, regulator and a rotameter to measure flow rates. Water wiil be supplied to the manifold by recirculating water drawn from the far end of the glass tank. A recycle water pump will supply the water for the water jet. The laboratory's water supply system can also supply fresh water for the sparger jet. The fresh water supply will primarily be used to fill the tank with water.

As proposed for the in the HWVP SBS design, the sparge section in the test stand wi1l be located 9 in. above the bottom of the tank, and 24 in. from the wa11. In Section 1, "Background and Testing Objectives," the HWVP SBS design specifies a $4 \mathrm{ft}$ diameter sparge ring with 24 sets of 3/32-in. holes, with 4 hote per set. The hole sets are uniformly spaced on the ring at $15^{\circ}$ arcs. Figure 3 shows a plan view of the test tank with an overlay of a $15^{\circ}$ sector of the HWVP SBS. For successful operation, each set of perforations on the sparge ring will be required to resuspended settled sediment in each sector.

One end of the test tank will be elevated approximately 3 inches so that the bottom of the test tank will be sloped to the same angle as the scrub tank fabricated for the LFCM-SBS $\left(3.8^{\circ}\right)$. For the LFCM scrub tank, which has an inside diameter of 60 inches, the bottom rises 4 inches (low end to high end).

A portable sampling manifold will be used to withdraw slurry samples while the jet is in operation. The sampling manifold will consist of a 30 inch long section of $1 / 8$ inch stainless steel tubing clamped to a 30 inch long . $1 / 2$ inch diameter dower. Flex hose will connect the sampling tube to a peristaltic pump. The pump will dispense the slurry into a beaker, and the sample will analyzed for wt\% solids. The manifold will be hand held in a vertical position perpendicular to the tank bottom. The dowel will always touch the bottom of the tank and the tube will be clamped at a set distance above the tank bottom. The clamps will allow the tube to be adjusted to different positions along the dowel so samples can be withdrawn at various 
depths within the tank. The sampling manifold is hand held to provide flexibility in the sampling locations within the tank.

Silica flour will be used for the sediment simulant during the preliminary stages of this evaluation. Two size classifications of silica flour will be used. It will be attempted to bracket the particle size distribution of the SBS sediment collected during. PSCM-23 with the two silica flour particle sizes.

6 


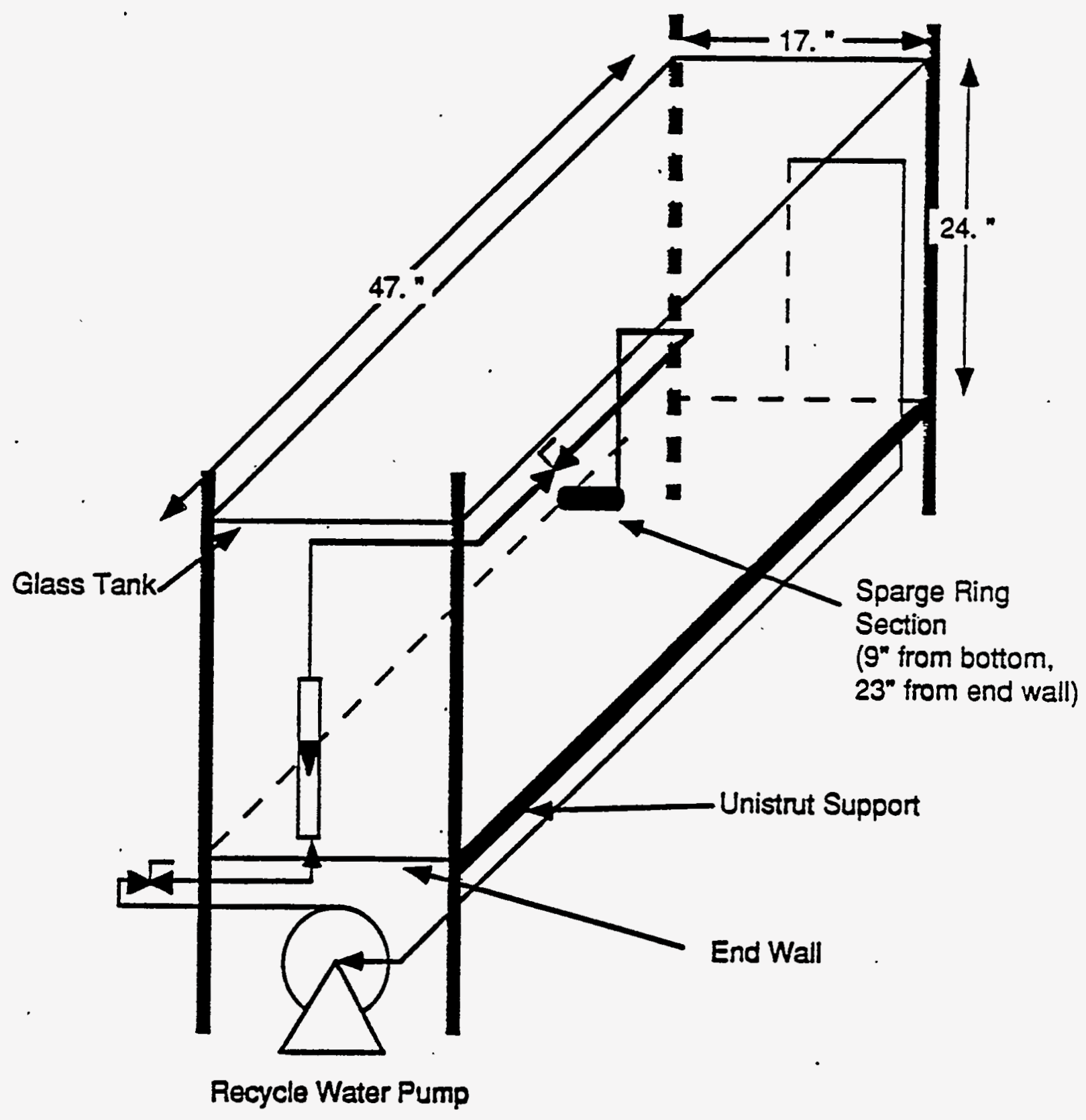

Figure 1. Configuration and Dimensions of Physical Model Test Stand for SBS Sparge Ring Evaluation 

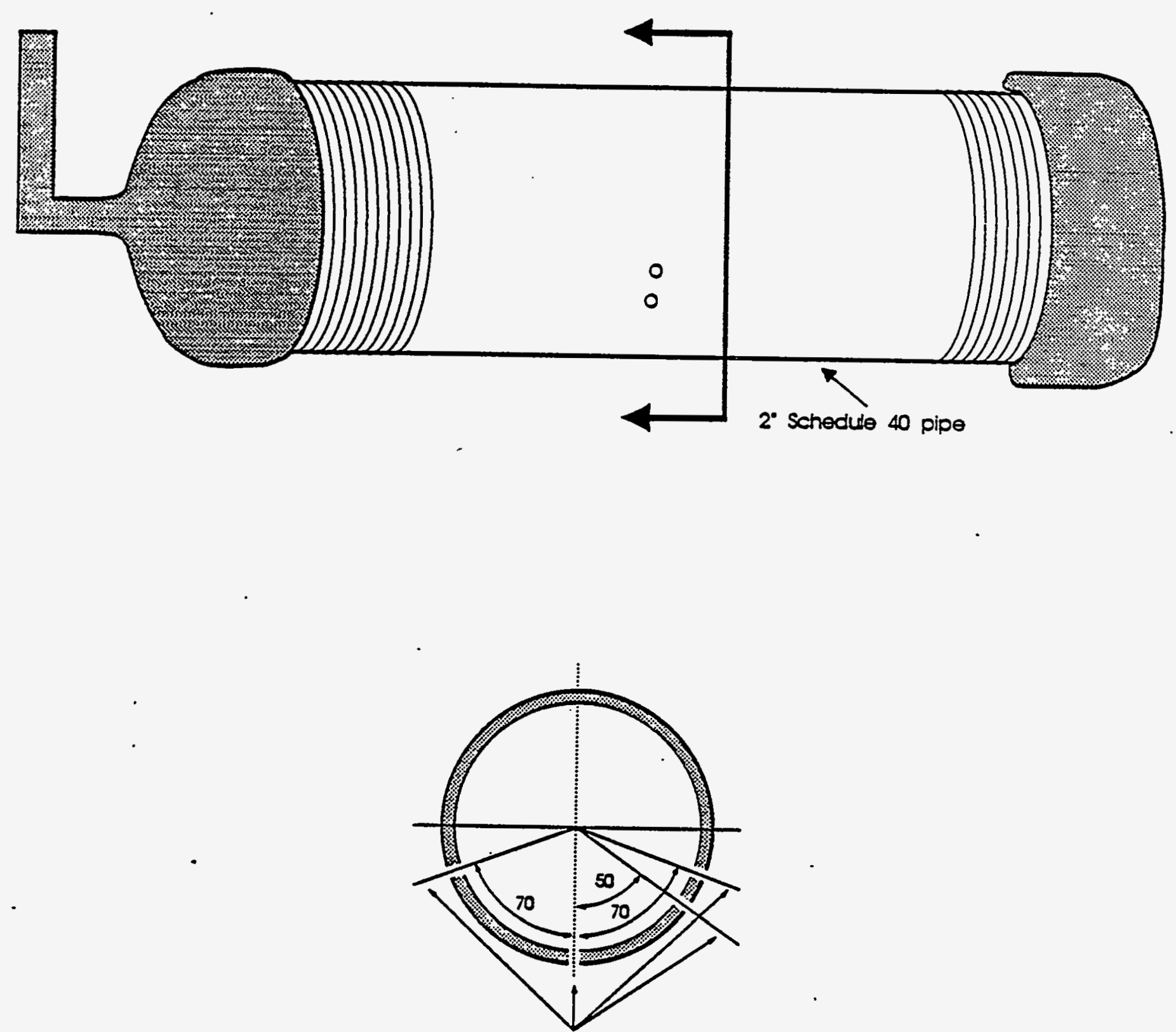

4 sets of $3 / 32$ holes

Figure 2. 6-inch Perforated Pipe Sparger 


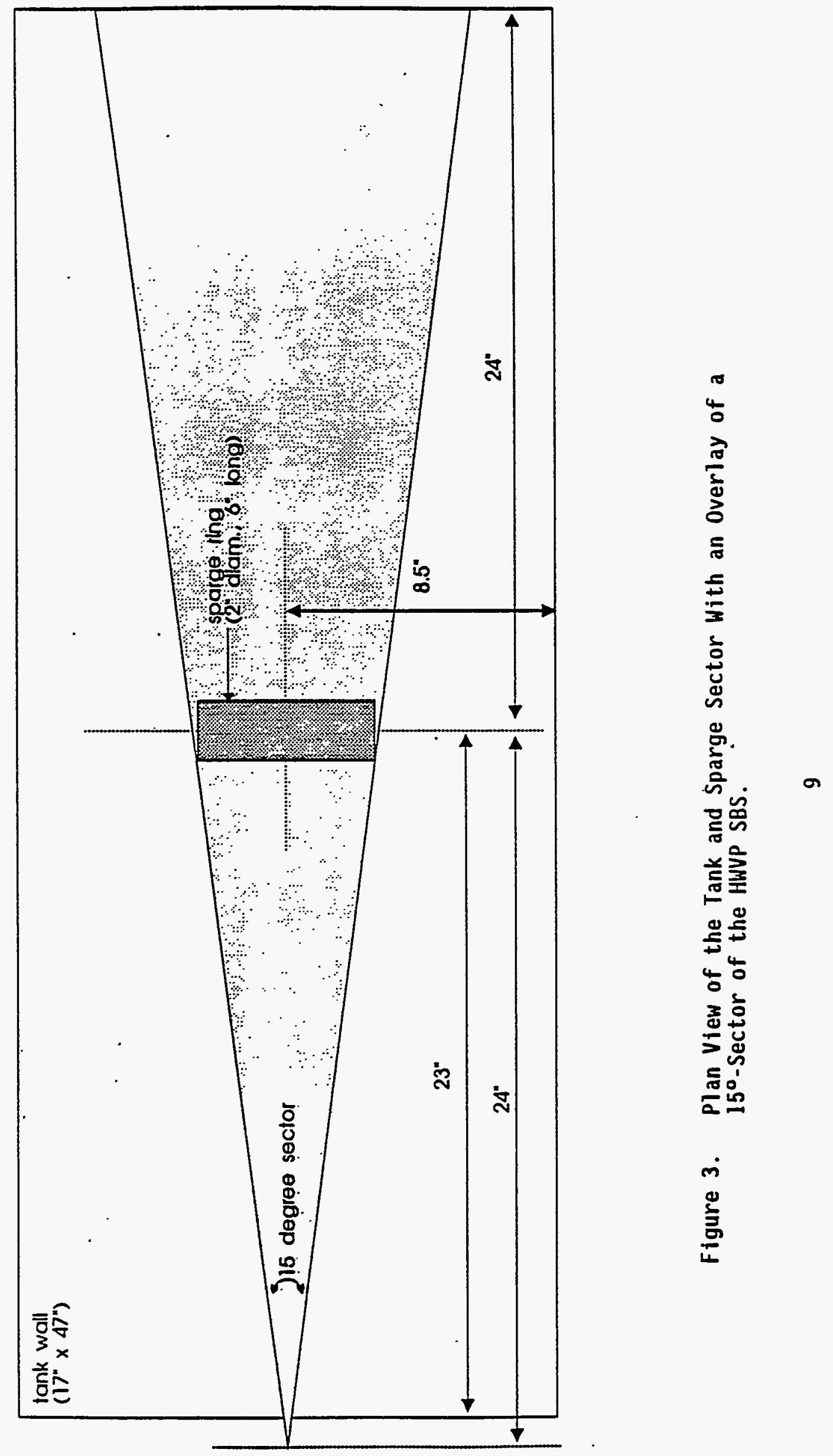




\subsection{EXPERIMENTAL METHODS}

\section{Jet Pattern}

The jet patterns and relative cleaning areas at various water flow ranges will be determined. Colored metal filings will be dropped into the water-filled tank while the sparger is in operation. The relative effective cleaning. area will be visually determined by observing the movement of the metal filings at different sparger flow rates

\section{Measured Parameters}

The location of the sparger in the tank will be recorded. Additionally, the position of the false wall will also be recorded.

The water (motive fluid) pressure and flow rates will be recorded for each experimental run. The water 7 ine has a pressure gage and rotameter to measure these parameters.

\section{Tank Homogeneity}

The tank homogeneity will be determined by visual observation and measuring the wt\% solids at various elevations and radial distances from the jet. A known weight of silica flour will be added to the water-filled tank. The quantity of silica added to the tank will be sufficient to form a layer approximately $1 / 2$ in depth inch on the tank bottom after settling for about 24 hours. During jet operation, samples of slurry will be taken, filtered, and oven dried. The amount of dry solids in the sample will be determined and compared to the amount of silica added to the tank. The sample location and its wt\% solids will determine the effectiveness of the silica resuspension for that particular jet operation.

From the WVDP SBS sedimentation evaluation testing, it was found that the silica addition method and the time silica was allowed to settle in the tank had a significant impact on the settled silica viscosity - which affected resuspension. The viscosity data indicated that after approximately $48 \mathrm{hrs}$ of setting time, the viscosity of the settled silica increased drastically. During the first 24 hours of setting time, the viscosity remained essentially constant. To insure that data from each run performed for the HWVP SBS sedimentation testing is comparable, the silica will initially be added to the 
tank in a slurry. Prior to each run, the silica will be thoroughly mixed ( 6 to 24 hours prior to testing) to uniformly distribute the silica across the tank bottom and to ensure that each run is conducted with a sediment that exhibits approximately the same viscosity.

During testing, after operating the sparge for 15 minutes, $100 \mathrm{~mL}$ slurry will be withdrawn from the tank at designated locations. The volume of the samples will be determined with a graduated cylinder. A peristaltic pump will extract the slurry from the tank and dispense it into a sample beaker. A Buchner funnel, filter paper, filter flask, and vacuum pump will be used to filter the slurry and collect the solids. Pre-cut \#5 Whatman filter papers will be dried and tared on the analytical balance. The paper will then be placed in the Buchner funnel and the funnel will be placed in the top of the filter flask. A flexible rubber hose will connect the flask to the vacuum pump. The pump will be turned on and the paper will be rinsed with deionized water to ensure that the paper is vacuum sealed to the funnel. The silica slurry will be dispensed from the beaker into the funnel and filtered through the paper under vacuum. The sample beaker and Buchner funnel will be rinsed with deionized water to collect all of the solids onto the filter paper. The vacuum pump will be shut off and the filter paper will be carefully removed from the funnel and placed on a glass drying dish. It will then be placed in a vacuum oven and dried for several hours at. $80^{\circ} \mathrm{C}$. Once drying is completed, the paper will be removed from the oven and weighed on the analytical balance. The weight of the dry solids will be calculated to determine the wt\% solids. This value will be compared to the overall wt\% solids of the tank to determine the tank homogeneity. This sampling process will be repeated several times at designated sampling locations for each test run. 


\subsection{TESTING MATRIX}

Based on the HWVP design and the experience gained from the WVDP SBS sediment resuspension evaluation, the following testing matrices have been developed:

TRACER PARTICLE TESTING MATRIX

\begin{tabular}{cccc}
$\begin{array}{l}\text { RUN } \\
\text { No. }\end{array}$ & $\begin{array}{c}\text { FLOW } \\
\text { RATE } \\
\text { (gDm) }\end{array}$ & $\begin{array}{c}\text { PRESSURE } \\
\text { (pSig) }\end{array}$ & $\begin{array}{c}\text { VISUAL OBSERVATION AND } \\
\text { MAPPING OF CLEANING AREA }\end{array}$ \\
\hline 1 & 1.0 & & \\
2 & 2.1 & & \\
.3 & 3.0 & &
\end{tabular}




\section{SILICA TESTING MATRIX}

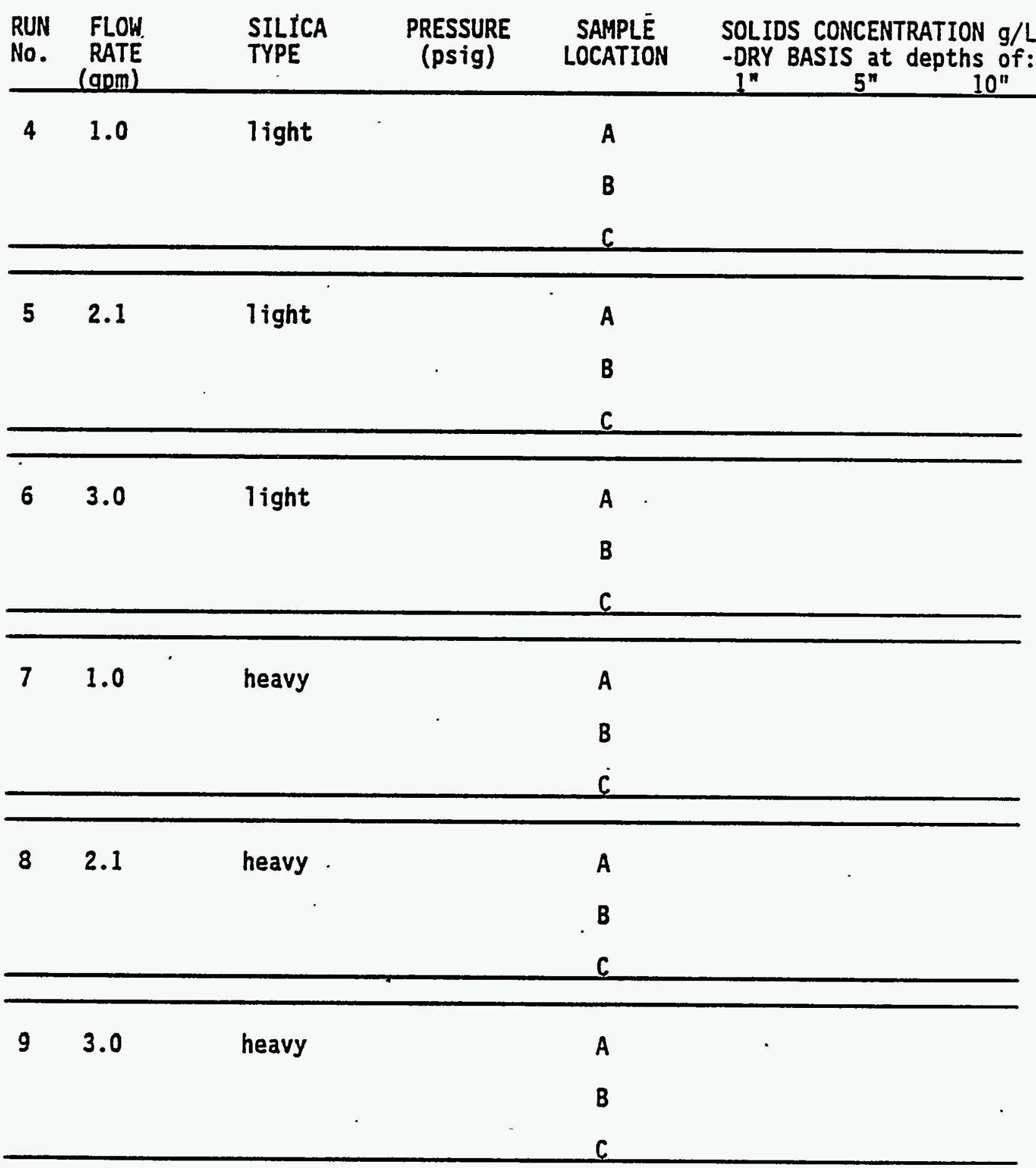




\subsection{TEST PREPARATIONS}

Impact Level

This activity has been designated Impact Level II, and as such, all work conducted under this test plan will be performed in accordance with Impact Level II quality assurance requirements as defined by WTC-006, Rev. 5. A1I data will be recorded in BNW Log Book BNW 54210.

Safety

All activities conducted under this test plan will be performed in accordance with approved safety procedures; including but not limited to safe use of the steam generator. Personnel involved in testing in the MDL building will be familiar with specific safety procedures for this facility and for handling silica flour.

\section{Personnel Training/Qualification}

Personnel involved in the SBS testing described in this test $p 1$ an shall be qualified for the work as required by PAP-70-201, and shall have read and understood these procedures and any special instructions or procedures related to this work.

Measuring and Testing Equipment

Equipment such as pressure gages, rotameters, and analytical balances will be properly calibrated and controlled in accordance with PAP-70-1201, Calibration Control System. A control list of the measuring and test equipment, as described in PAP-70-1201 will be prepared prior to initiating the experimental work. The following table contains the types of measuring and test equipment to be used during single jet testing. 
TABLE 1. Types of Measuring and Test Equipment To Be Used During Single Jet Testing

\begin{tabular}{lc} 
Measurement & $\begin{array}{c}\text { Expected Accuracy. (as per cent } \\
\text { actual measurement) }\end{array}$ \\
\hline Pressure & $+/-10 \%$ \\
Flow Rate & $+/-10 \%$ \\
wt\% Solids & $+/-3 \%$
\end{tabular}

